Article

\title{
Improved DisTrad for Downscaling Thermal MODIS Imagery over Urban Areas
}

\author{
Wiesam Essa ${ }^{1}$, Boud Verbeiren ${ }^{2}$, Johannes van der Kwast ${ }^{3}$ and Okke Batelaan ${ }^{4, *}$ \\ 1 Geospatial Data Center for Education, Research and Development (GDC), Al-Aqsa University, \\ Gaza Strip 0970, Palestine; Wiesam@alaqsa.edu.ps \\ 2 Department of Hydrology and Hydraulic Engineering, Vrije Universiteit Brussel, Pleinlaan 2, \\ BE-1050 Brussels, Belgium; Boud.Verbeiren@vub.be \\ 3 IHE Delft Institute for Water Education, Westvest 7, 2611 AX Delft, The Netherlands; \\ h.vanderkwast@un-ihe.org \\ 4 National Centre for Groundwater Research and Training (NCGRT), College of Science and Engineering, \\ Flinders University, Sturt Road, Bedford Park South Australia 5042, GPO Box 2100, Adelaide, \\ SA 5001, Australia \\ * Correspondence: okke.batelaan@flinders.edu.au; Tel.: +61-88-201-2269
}

Received: 22 October 2017; Accepted: 26 November 2017; Published: 1 December 2017

\begin{abstract}
Spaceborne thermal sensors provide important physical parameters for urban studies. However, due to technical constraints, spaceborne thermal sensors yield a trade-off between their spatial and temporal resolution. The aims of this study are (1) to downscale the three originally low spatial resolution $(960 \mathrm{~m}$ ) Moderate Resolution Imaging Spectroradiometer (MODIS/Terra) land surface temperature image products (MOD11_L2, MOD11A1 and MOD11A2) to resolutions of 60, 90, 120, 240 and $480 \mathrm{~m}$; and (2) to propose an improved version of the DisTrad method for downscaling the MODIS/Terra land surface temperature products over urban areas. The proposed improved DisTrad is based on a better parameterization of the original DisTrad residuals in urban areas. The improved resampling technique is based on a regression relationship between the residuals of the temperature estimation and the impervious percentage index. Validation of the improved DisTrad, the original DisTrad, and the uniformly disaggregated MODIS land surface temperature images (UniTrad) are performed by comparative analysis with a time-coincident Landsat 7 ETM+ thermal image. Statistical results indicate that the improved DisTrad method shows a higher correlation $\left(R^{2}=0.48\right)$ with the observed temperatures than the original DisTrad $\left(R^{2}=0.43\right)$ and a lower mean absolute error $\left(\mathrm{MAE}=1.88^{\circ} \mathrm{C}\right)$ than the original DisTrad $\left(\mathrm{MAE}=2.07^{\circ} \mathrm{C}\right)$. It is concluded that the improved DisTrad method has a stronger capability to downscale land surface temperatures in urban areas than the original DisTrad.
\end{abstract}

Keywords: land surface temperature; downscaling; disaggregation; impervious percentage; DisTrad; MODIS; Landsat 7 ETM+

\section{Introduction}

Land surface temperature (LST) is a key parameter in numerous scientific studies [1]. It is used as an input parameter in surface energy balance algorithms to make estimates of net radiation, sensible and latent heat flux, thermal inertia, precipitation, evapotranspiration, and urban-induced surface runoff [2]. Also for urban sciences, it is of prime importance, as, e.g., in evaluating urban climates [3].

Cities are known to be complex areas for remote sensing based image classification and thermal pattern differentiation due to the high variability of land-cover types and construction materials. Consequently, heterogeneity or mixed pixel problems limit automatic pattern identification from thermal and visual bands at low resolutions. Construction materials typically used in urban areas, 
such as concrete, roofing, asphalt, etc., are characterized by a high heat capacity, high heat conductivity, low albedo, low emissivity and low permeability [2]. These specific physical thermal characteristics of the urban zone yields considerable temperature differences in contrast with the generally cooler rural periphery, a phenomenon that is defined as urban heat island (UHI).

Studying and monitoring urban heat island effects through spaceborne remote sensing requires land surface temperature image data at high spatial and temporal resolution. However, due to technical constraints, satellite-borne thermal sensors yield a trade-off between their spatial and temporal resolution (Table 1). Consequently, a higher spatial resolution is often associated with a low temporal resolution and vice versa. To capture the complex land surface temperature changes of the urban environment, e.g., at the scale of building blocks and individual street canyons [4], very high resolution (5-10 m) land surface temperature measurements from aircraft are needed [5]. However, satellite-derived land surface temperature image data at the scale of $100 \mathrm{~m}$ can be considered adequate for depicting most of the intra-urban variations of land surface temperature related to urban morphology [6].

Table 1. Technical characteristics of operational thermal satellite sensors.

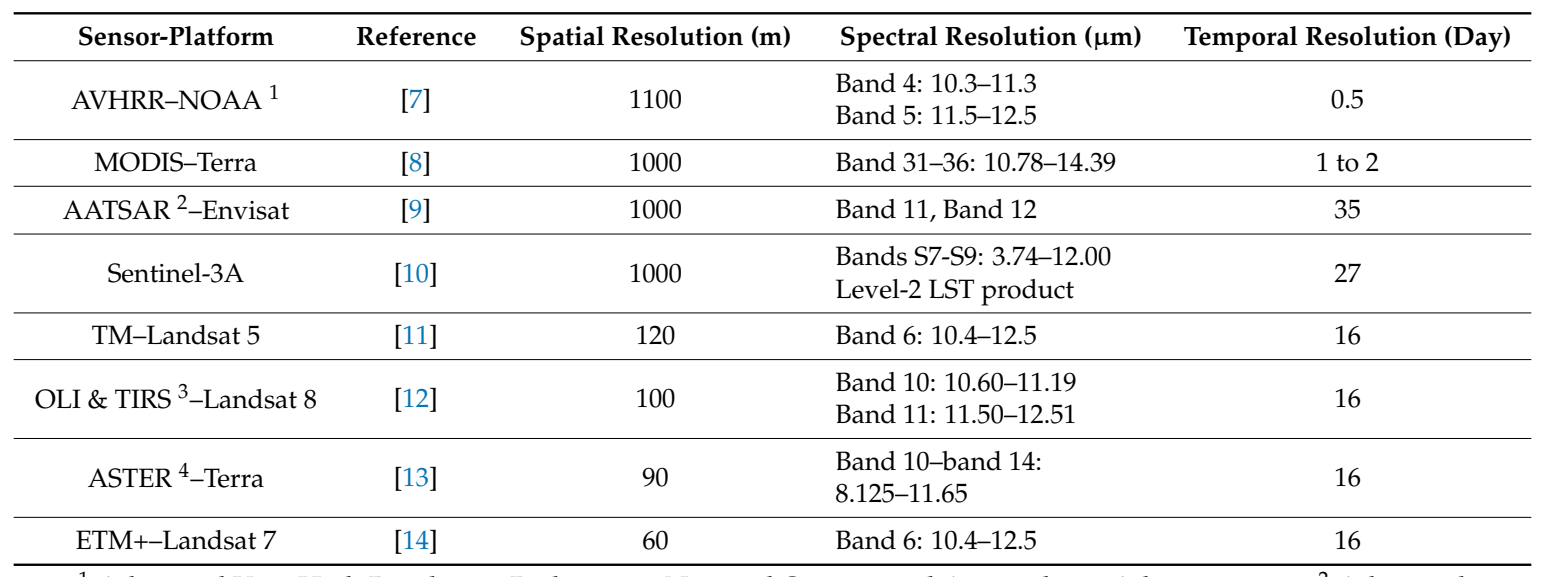

${ }^{1}$ Advanced Very High Resolution Radiometer-National Oceanic and Atmospheric Administration; ${ }^{2}$ Advanced Along-Track Scanning Radiometer; ${ }^{3}$ Operational Land Imager and Thermal Infrared Sensor; ${ }^{4}$ Advanced Spaceborne Thermal Emission and Reflection Radiometer.

Spaceborne sensors with thermal bands, such as the Moderate-Resolution Imaging Spectrometer (MODIS) and Sentinel, have become readily available in recent years. MODIS (http://modis.gsfc. nasa.gov) provides daily thermal band imagery at $1 \mathrm{~km}$ spatial resolution, which is too coarse for temperature mapping in highly fragmented urban and sub-urban areas. The thermal bands of MODIS and other thermal sensors may provide better results for UHI studies when downscaling is applied [15]. MODIS generates reliable and consistent long-term series of land surface temperature and emissivity (LST\&E) products, which are important for a broad scientific community in monitoring and understanding land-use and land-cover change and potential impacts of climate variability.

Thermal sharpening is a promising technique for the mixed pixel problem. Various thermal sharpening techniques for unmixing land surface temperature have been developed during the last 15 years for vegetated areas. Given the fact that the algorithms for retrieving land surface temperatures from remotely sensed Thermal Infrared (TIR) radiance images are well-established [16-19], it became cost-efficient to produce downscaled images especially compared to high-resolution imagery. Examples of those techniques are the Multisensor Multiresolution Technique (MMT) [20], Pixel Block Intensity Modulation (PBIM) [2], Disaggregation of radiometric surface temperature (DisTrad) [21], algorithm for Thermal imagery Sharpening (TsHARP) [22], the scale-invariant physical model for TIR radiance [23], and High-Resolution Urban Thermal Sharpener (HUTS) [24]. Testing of these techniques is mostly still in a beginning stage and, in particular, their possible use for urban areas has not been thoroughly evaluated.

Voogt and Oke [25] suggest that the use of remotely sensed parameters such as Normalized Difference Vegetation Index (NDVI) and other high-resolution multispectral remotely sensed 
information, e.g., derived from IKONOS imagery, may contribute to a better characterization of the urban surface as it increases the understanding of remotely observed thermal imagery. Spectral indices provide a useful basis for developing methods to downscale land surface temperature for different land-cover types. Essa et al. [26] compared the functional relationship for 16 different spectral indices. The results showed that sub-pixel impervious percentage index (I\%) yields a better relation to downscale land surface temperature in urban areas than NDVI. Similar conclusions are also shown in other publications [27-29], which show for different cities a stronger relationship of impervious percentage than NDVI with land surface temperature.

Essa et al. [26] used DisTrad to improve downscaling of land surface temperature over the city of Dublin (Figure 1). The basic idea of the DisTrad downscaling method was to establish a land-cover based functional regression between low-resolution thermal information and higher resolution parameters such as NDVI [21] or vegetation fraction for vegetated areas [22] and impervious percentage for urban areas [29].

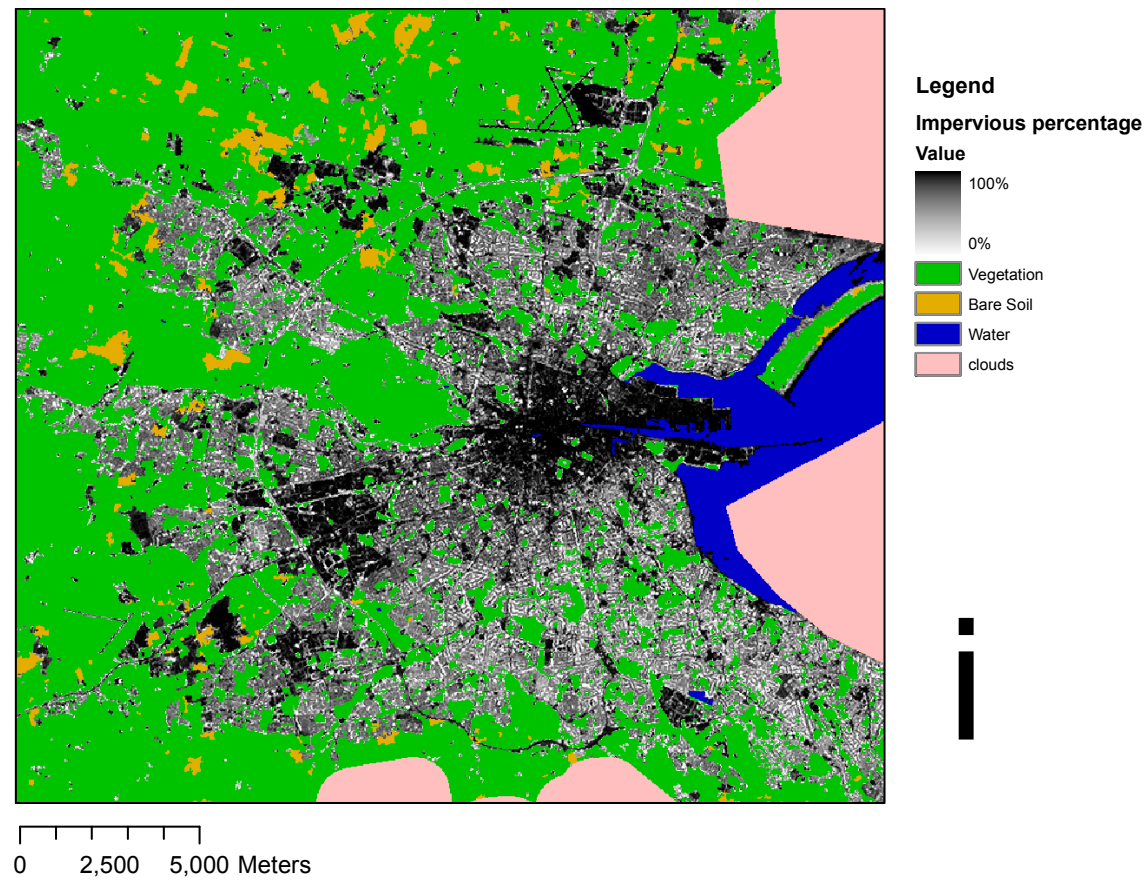

Figure 1. Land-use/land-cover map indicating the percentage of impervious surface within the urban mask in gray shades $([26,30]$ (with permission from Elsevier)).

In the last years, the downscaling framework of DisTrad was proposed based on the relationship between land-surface temperature (LST) and different spectral remote sensing indices as indicators of different land covers, which gained much attention due to their simplicity, physical basis, and operational capability [31]. The relationship was obtained from coarse-resolution (CR) pixels and applied to the fine-resolution (FR) pixels. An accurate evaluation of the disaggregation method performances requires researchers to first identify all the possible errors/controls that may affect the associated evaluation [32]. The temperature estimation residuals in DisTrad are caused by other cooling and/or heating factors affecting the relationship of the parameter used with land surface temperature [26]. The relationship obtained was also applied at CR to obtain the difference between the original and predicted LST (residuals). The CR residuals were then added to the estimated LST at FR; this means that the same residual was used in all the FR pixels belonging to the same CR pixel. "Adding residuals back" to predicted FR LST violates the constrain that means that FR pixels should equal to the equivalent coarse resolution pixel [33]. If the residual error is kept constant it causes discontinuities in the spatial representation, which results in a "boxy effect" in the downscaled image [33-36]. The ratio 
between the CR and the FR is responsible for this boxy effect, and lower differences between the spatial resolutions would mitigate this boxy effect [36]. The resolution ratio usually ranges from several times (e.g., from $\sim 100$ to $30 \mathrm{~m}$ for the downscaling of Landsat thermal images) [32] to as large as several tens of times (e.g., from $\sim 5000$ to $100 \mathrm{~m}$ for the downscaling of geostationary thermal images) [37]. The difficulty is then to develop a general framework in which these cooling and/or heating factors can be consistently integrated into the downscaling procedure [38]. A new trend of advancing the DisTrad framework is to adjust the residuals estimation before adding it up to the final LST product. There are very few studies, which examine comprehensively the smoothing of residuals in thermal sharpening over agricultural and natural landscapes, e.g., using a Gaussian filter [39] and the NL-DisTrad method [40]. Bindhu et al. [40] developed the nonlinear DisTrad (NL-DisTrad) model in which the residuals generated at coarse spatial resolution are modelled using an artificial neural network (ANN) model. The goal of this article is to smooth and model the residuals with impervious percentage (I\%) for a heterogeneous urban environment and to evaluate this model.

The city of Dublin (Ireland) is selected as a study area to evaluate and improve the DisTrad algorithm because land surface temperature and impervious percentage cover a wide range of values. This study first evaluates the effectiveness of the uniformly disaggregated MODIS/Terra land surface temperatures (UniTrad), the original DisTrad method, and the improved version of DisTrad to downscale MODIS/Terra land surface temperature products over urban areas. A coincident land surface temperature product of Landsat 7 ETM+ is used to evaluate the results. Correlation analysis and goodness of fit measures, i.e., Root Mean Square Error (RMSE) and Mean Absolute Error (MAE), are used to quantitatively evaluate the results. A further objective is to downscale six MODIS/Terra land surface temperature image products (Figure 2), which are described in detail in Section 2.
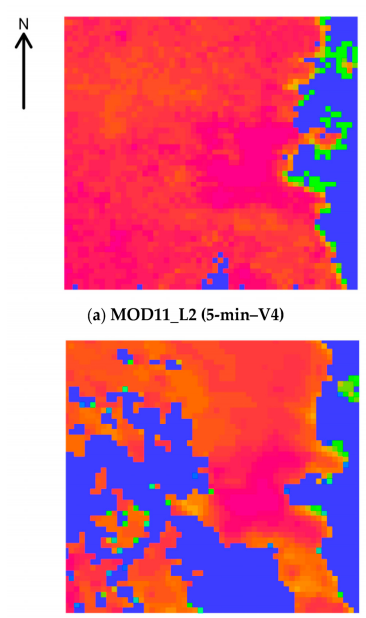

(c) MOD11A1 (1-Day-V4)

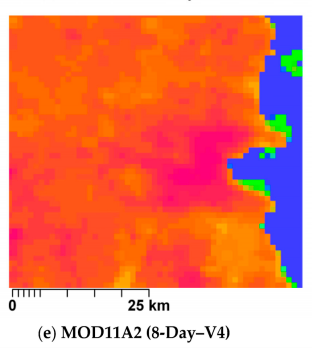

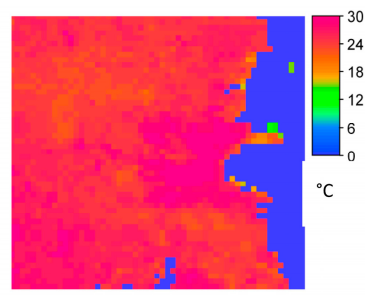

(b) MOD11_L2 (5-min-V5)

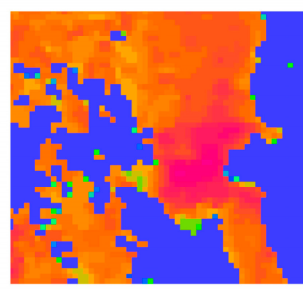

(d) MOD11A1 (1-Day-V5)

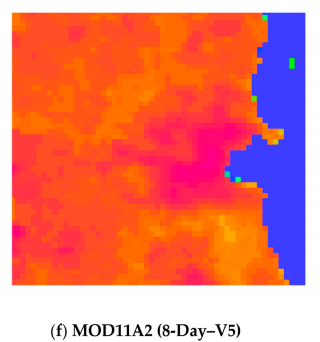

Figure 2. MODIS/Terra land surface temperature (in ${ }^{\circ} \mathrm{C}$ ) products used in this study including, $(\mathbf{a}, \mathbf{b}) 5$ min product; (c,d) 1 day product; and (e,f) 8 days product; with two different collection methods (V4 and V5), at $960 \mathrm{~m}$ resolution.

Downscaling was applied to obtain land surface temperatures from the original $960 \mathrm{~m}$ resolution to higher resolutions of 60, 90, 120, 240, and $480 \mathrm{~m}$. Evaluation with the coincident thermal Landsat 7 
ETM+ image was used to evaluate the downscaled products of the 5-min MODIS/Terra land surface temperature. However, a validation to evaluate the downscaled products of the temporally averaged MODIS/Terra land surface temperature images, 1-Day MODIS/Terra product MOD11A1 and 8-Day MODIS/Terra product MOD11A2, was not possible because of its difference in time coverage.

\section{Materials and Methods}

\section{Remote Sensing Data}

Figure 1 presents the study area. The City of Dublin is bounded by the longitudes $6^{\circ} 00^{\prime}$ and $6^{\circ} 48^{\prime}$ West and latitudes $53^{\circ} 07^{\prime}$ and $53^{\circ} 35^{\prime}$ North, covering an area of about $2700 \mathrm{~km}^{2}$. A land-cover map (LC) including an impervious percentage map (I\%) for the urban class is available [41]. The combined result is shown in Figure 1 and was also used in Essa et al. [26,29]. The high variability of the impervious percentage shows how heterogeneous the urban landscape pattern is, with higher densities occurring in the urban core (e.g., administrative and commercial zones; industrial areas along the coast line) and lower densities in the periphery (e.g., suburban residential neighborhoods with extensive grass and tree covered zones). The wide range of impervious percentage and surface temperatures in Dublin city makes the area an adequate case to evaluate an improved DisTrad methodology for land surface temperature downscaling over urban areas.

Land surface temperature (MOD11-L2) of MODIS/Terra official product consists of a $928 \mathrm{~m}$ resolution image, which is retrieved by the generalized split window algorithm [17,18]. It is registered in a sinusoidal projection. Prior to downscaling MODIS/Terra land surface temperature products, the data were re-projected from sinusoidal to geographic latitude/longitude using the HDF-EOS (Hierarchical Data Format-Earth Observing System) to GeoTIFF Conversion Tool (HEG) (http://newsroom.gsfc.nasa.gov/sdptoolkit/HEG/HEGHome.html). All images were initially geo-registered to the same reference system of UTM Zone 29N/WGS84 prior to downscaling. If the land surface temperature was not produced due to, e.g., the presence of cloud cover, these values were set to no data. Quality Control (QC) information included with the MOD11B1 product allows evaluation of the Quality Assurance (QA) [42]. QA is generated during production of MODIS/Terra land surface temperature products, or in post-product scientific and quality checks of the data product. QA is fully automatically set according to calculation rules and algorithms based on data conditions encountered during a run of the LST algorithm; accordingly, pixel values are set to "Failed" or "Passed".

Three different product types (MOD11_L2, MOD11A1, and MOD11A2), collected in two different ways (V4 and V5) are used. The first product, MOD11_L2, constitutes of $1 \mathrm{~km}$ pixels, which are produced at 5-min increments using the generalized split-window land surface temperature algorithm. Geolocation data at a coarse resolution is stored in the product. The second product, MOD11A1, is a tile of the daily land surface temperature product, which is generated by mapping the pixels in the MOD11_L2 products for a day to the Earth locations on the sinusoidal projection. The third product, MOD11A2, is an eight-day land surface temperature product, which is generated by averaging two to eight days of the MOD11A1 products.

Six images of MODIS/Terra land surface temperature products, generated by two different collection methods, Collection 4 (V4) and 5 (V5) are used. In both V4 and V5, the algorithm used for calculating land surface temperature is the generalized split window algorithm $[17,18]$. The technical characteristics of these images are listed in Table 2. MODIS Land-surface Temperature/Emissivity (LST\&E) products generated from the Product Generation Executive (PGE) code (Collection 5) are more recent and contain major refinements in comparison to V4. Collection 5 products are extensively discussed in Wan [42] and principal refinements can be summarized as follows: (1) the grid size of LST/emissivity from the day/night algorithm increases from $5 \mathrm{~km}$ (V4) to $6 \mathrm{~km}$; (2) the number of sub-ranges of viewing angles increases from 5 to 16 for the day/night algorithm; (3) an option for combined use of Terra and Aqua MODIS data in the day/night LST algorithm is added; (4) the slope effect in the $6 \mathrm{~km}$ grids is considered in the QA of the LST/emissivity results from the day/night 
algorithm; (5) the viewing angle dependent generalized split-window method is fully incorporated into the day/night algorithm; (6) no temporal averages in the generation of the $1 \mathrm{~km}$ LST product (MOD11A1 and MYD11A1) are made per request of the user community; (7) the surface air temperature (as in V3.0.0 PGE16) is interpolated from the atmospheric temperature profile in MOD07.

Table 2. Scene characteristics of LST MODIS/Terra land surface temperature products used for downscaling and the observed Landsat 7 ETM+ land surface temperature (Band 6-low gain). Data calculated at $960 \mathrm{~m}$ resolution with $99 \%$ of the value range.

\begin{tabular}{|c|c|c|c|c|c|c|c|}
\hline \multirow{2}{*}{$\begin{array}{c}\text { MODIS/Terra } \\
\text { Temperature Products }\end{array}$} & \multirow{2}{*}{$\begin{array}{l}\text { Collection } \\
\text { Version }\end{array}$} & \multirow{2}{*}{$\begin{array}{l}\text { Acquisition } \\
\text { Time }\end{array}$} & \multirow{2}{*}{$\begin{array}{l}\text { Acquisition } \\
\text { Date }\end{array}$} & \multicolumn{4}{|c|}{ MODIS 24 May 2001 Original Temperatures $\left({ }^{\circ} \mathrm{C}\right)$} \\
\hline & & & & Min & Max & Value Range & Mean \\
\hline MOD11_L2 (5 min) & V4 & 11:45-11:50 & 24-05-01 & 14.39 & 32.55 & 18.16 & 27.53 \\
\hline MOD11_L2 (5 min) & V5 & 11:45-11:50 & 24-05-01 & 21.55 & 32.51 & 10.96 & 27.95 \\
\hline MOD11A1 (1 day) & V4 & $11.17-22: 33$ & 24-05-01 & 3.29 & 27.05 & 23.76 & 22.10 \\
\hline MOD11A1 (1 day) & V5 & 00:00-23:59 & 24-05-01 & 7.35 & 29.91 & 22.56 & 24.14 \\
\hline MOD11A2 (8 days) & V4 & 00:00-23:59 & $(17-24)-05-01$ & 9.41 & 29.11 & 19.7 & 24.59 \\
\hline MOD11A2 (8 days) & V5 & 00:00-23:59 & $(17-24)-05-01$ & 7.59 & 29.61 & 22.02 & 25.05 \\
\hline \multirow{2}{*}{ Landsat 7 ETM+ } & \multirow{2}{*}{$\begin{array}{l}\text { Collection } \\
\text { Version }\end{array}$} & \multirow{2}{*}{$\begin{array}{l}\text { Acquisition } \\
\text { Time }\end{array}$} & \multirow{2}{*}{$\begin{array}{l}\text { Acquisition } \\
\text { Date }\end{array}$} & \multicolumn{4}{|c|}{ Landsat 7 ETM+ 24 May 2001 Temperatures $\left({ }^{\circ} \mathrm{C}\right)$} \\
\hline & & & & Min & Max & Value Range & Mean \\
\hline Band 6 converted to LST & & 11:30 & 24-05-01 & 23.59 & 38.83 & 15.24 & 32.97 \\
\hline
\end{tabular}

\section{Thermal Downscaling Method}

\subsection{Original DisTrad}

The original DisTrad method was developed by Kustas et al. [21] for downscaling land surface temperature in homogenous vegetated landscape. The linear regression relationship between the land surface temperature product and NDVI, at low resolution, is considered as a useful basis for estimating land surface temperature at higher resolutions. Recently, several studies showed some limitations of using NDVI-based approaches on agricultural areas [22,34,38,43]. The DisTrad method was therefore adapted by Agam et al. [22,34] by replacing the NDVI with the fractional vegetation cover, renaming the method to TsHARP for downscaling land surface temperature in vegetated area. The original DisTrad method is also adapted in Essa et al. [26] for downscaling land surface temperature in heterogeneous urban landscapes. This study compared not only the NDVI but also 15 other spectral remote sensing indices, based on the correlation with land surface temperature. The study revealed that impervious percentage was the most successful biophysical indicator over urban areas to estimate land surface temperature. Moreover, other studies $[27,28,44]$ found that NDVI is less suitable for downscaling high resolution land surface temperature images, e.g., Landsat 7 ETM+ from 60 to $30 \mathrm{~m}$ [26], or for downscaling low resolution land surface temperature images, e.g., MODIS from 960 to $60-480 \mathrm{~m}$ [29], due to the low vegetation cover within the urban fabric.

Kustas et al. [21] and Agam et al. [22] indicated that a first order linear regression is more preferable because it yields a higher coefficient of determination $\left(\mathrm{R}^{2}\right)$. A second order fit may be unduly influenced by outliers at high and low NDVI values, caused, for example, by unresolved water bodies or urban structures, potentially yielding poor retrievals [21,22]. Applying a first order linear function to urban areas has shown the advantage of being less sensitive to the upper and lower tails (outliers) of the impervious percentage distribution than other higher order linear models and nonlinear models (e.g., exponential).

The adapted DisTrad thermal downscaling based on impervious percentage is described in Essa et al. [26,29]. A unique linear relationship between land surface temperature (dependent variable) and impervious percentage (independent variable) is assumed at the low resolution of the MODIS/ Terra land surface temperature products. To illustrate this adapted DisTrad approach, the procedure to downscale land surface temperature from 960 to $60 \mathrm{~m}$ resolution will be described in detail.

Kustas et al. [21] show that a selection of uniform NDVI pixels increases the correlation $\left(R^{2}\right)$ with land surface temperature and decreases the root mean square error (RMSE) when using a least 
squares fit at low resolution. Kustas et al. [21] recommend a selection of $25 \%$ of the pixels of the independent variable with the lowest coefficient of variance (CV). They assume that this subset is representative for the whole set of pixels. Essa et al. [26] confirm that the $25 \%$ threshold of impervious percentage gives the best correlation with Landsat $7 \mathrm{ETM}+$, when temperatures are downscaled from 60 to $30 \mathrm{~m}$. However, in the case of downscaling MODIS land surface temperatures from $960 \mathrm{~m}$ to higher resolutions $(60 \mathrm{~m}, 90 \mathrm{~m}, 120 \mathrm{~m}, 240 \mathrm{~m}$, and $480 \mathrm{~m})$, a selection of $50 \%$ of the most homogeneous low resolution pixels gives the best correlation [29]. The detailed procedure on the selection of the uniform pixels based on the CV is described in [26,29].

The different steps to downscale MODIS/Terra land surface temperature products from 960 to $60 \mathrm{~m}$ resolution using the original DisTrad method are as follows:

(1) A least-squares fit is performed between the MODIS/Terra land surface temperature product MOD_LST 960 (dependent variable) and the upscaled impervious percentage map I $_{960}$ (independent variable), which was derived by spatial averaging of the $30 \mathrm{~m}$ impervious percentage map:

$$
\text { MOD_LST }_{960}=\mathrm{a}_{0}+\mathrm{a}_{1} \mathrm{I}_{960}
$$

where $\mathrm{a}_{0}$ and $\mathrm{a}_{1}$ are, respectively, the intercept and regression coefficient of the least square regression.

(2) Calculate the estimated land surface temperature at the low resolution $\bar{T}_{960}$ (the resolution of the observed land surface temperature product-MODIS resolution) and the estimated land surface temperature at the high resolution $\overline{\mathrm{T}}_{60}$ (target resolution for downscaling). The overbar symbol of $\mathrm{T}$ is used to indicate an estimated temperature based on a least-squares equation:

$$
\begin{gathered}
\overline{\mathrm{T}}_{960}=\mathrm{a}_{0}+\mathrm{a}_{1} \mathrm{I}_{960} \\
\overline{\mathrm{T}}_{60}=\mathrm{a}_{0}+\mathrm{a}_{1} \mathrm{I}_{60}
\end{gathered}
$$

whereby $\mathrm{I}_{960}$ and $\mathrm{I}_{60}$ are the impervious percentage derived from the Landsat 7 ETM+ bands at $30 \mathrm{~m}$ resolution and aggregated to $960 \mathrm{~m}$ and $60 \mathrm{~m}$ resolution respectively; $\mathrm{a}_{0}$ and $\mathrm{a}_{1}$ are the regression coefficients of Equation (1).

(3) Calculate the temperature estimation residuals $\left(\Delta \overline{\mathrm{T}}_{960}\right)$, as the difference between the observed (original) MODIS/Terra land surface temperatures product (MOD_LST 960 ) and the estimated temperature $\left(\overline{\mathrm{T}}_{960}\right)$ at the low resolution, resulting from Equation (2):

$$
\Delta \overline{\mathrm{T}}_{960}=\text { MOD_LST } 960-\overline{\mathrm{T}}_{960}
$$

The temperature estimation residuals represent the divergence of the estimated temperatures from the observed temperatures in urban areas, due to spatial variability in land surface temperature. These are caused by factors affecting the land surface temperature-impervious percentage relationship [26]. Essa et al. [29] defines these factors as heating and/or cooling phenomena, such as meteorological circumstances (moisture, sea current, wind speed etc.), urban structure design, presence of green and open areas, thermo-physical characteristics of impervious surfaces, mixed pixels, etc.

(4) The final step is to add the temperature estimation residuals at $960 \mathrm{~m}$ resolution (Equation (4)) to the estimated land surface temperature at the high resolution $\overline{\mathrm{T}}_{60}$. Therefore, these residuals are resampled to match the sharpening target resolution (in this example, $60 \mathrm{~m}$ ), represented by $\Delta \overline{\mathrm{T}}_{60}$ in Equation (5). The sharpened temperature image $\overline{\mathrm{T}}_{60}$ sharp is finally obtained using Equation (5):

$$
\overline{\mathrm{T}}_{60} \text { sharp }=\overline{\mathrm{T}}_{60}+\Delta \overline{\mathrm{T}}_{60}
$$

\subsection{Improved DisTrad}

It is the aim to improve DisTrad by adjusting the temperature estimation residuals $\Delta \overline{\mathrm{T}}$ (final step of the original DisTrad procedure). Originally, simple resampling was used to obtain temperature 
estimation residuals at the desired resolution. This involves a simple overlay operation, where the values at the higher resolution are the same as at the low resolution within one low resolution pixel, e.g., one MODIS $960 \mathrm{~m}$ pixel corresponds to 256 pixels of $60 \mathrm{~m}(16 \times 16)$, and the temperature estimation residuals for all these pixels will be equal to the one of the low resolution pixel.

The effects of scale have already been widely discussed. In literature, there is an ongoing discussion with contradicting conclusions whether remote sensing products are scale dependent or not [45]. The main reason is that the scaling effects are usually dependent on the application. Different spatial processes may operate at different scales, and thus conclusions based on one scale may not be applicable to another scale [45]. Spatial patterns are also scale dependent. Spatial patterns may look like a cluster at one scale but random at another [46].

In the original DisTrad method, it is assumed that the temperature estimation residuals, which are caused by processes dominant at the kilometer scale of MODIS, have the same magnitude at a higher resolution. However, the dominant processes are not the same at different scales, and they may need different retrieval models for different scales [45]. Depending upon the observation scale, the process, which appears homogeneous at a local scale, may become heterogeneous at a large scale and factors that are important at one scale may become trivial at another, especially if we consider processes in heterogeneous urban areas [45,47-49]. To conclude, the original DisTrad method, which resamples the temperature estimation residuals calculated at the low resolution using simple resampling techniques introduces an uncertainty.

In this study, it is proposed to revise the DisTrad sharpening procedure by using the correlation between the impervious percentage and the temperature estimation residuals generated from the two MODIS/Terra 5-min land surface temperature products (V4 and V5).

\subsection{Improving Impervious Percentage-LST Relationship}

Impervious percentage mapping, data extraction and modelling techniques with the objective to analyze thermal characteristics of urban land-cover (LC) types are widely spread [50]. However, refining the relationship between impervious percentage and land surface temperature using geostatistical techniques suitable for remote sensing data are not yet fully developed. Every city is unique in terms of its spatial patterns of imperviousness, as well as its internal characteristics, e.g., type of construction materials or external characteristics, e.g., climate conditions. Wu and Li [45] state that downscaling methods based on land surface temperature products, such as DisTrad, are fairly simple to apply, but the obtained regression fit is usually site, time, model and scale dependent. If any factor is changed, the relationship may need to be recalibrated. In short, the relationship between impervious percentage and land surface temperature is city and image dependent.

When all pixels are considered within the scatter space of impervious percentage versus land surface temperature at low resolution, a considerable regression error is obvious, due to the fact that certain pixels will deviate from the main regression line. Essa et al. [29] show that taking a sub-selection of the most uniform pixels of impervious percentage by using different thresholds of the coefficient of variance will result in different relationships, when the selected pixels are plotted against simulated MODIS thermal resolution. The selection of uniform pixels is based on the lowest coefficient of variance (CV). Essa et al. [29] compare four scenarios using thresholds of $25 \%, 50 \%, 75 \%$, and $100 \%$ of the impervious percentage pixels with the lowest $\mathrm{CV}$. The best correlation between impervious percentage and the simulated MODIS land surface temperature in Dublin city was obtained when using a 50\% threshold value. The regression analysis yields a high correlation $\left(R^{2}=0.78\right)$ and a low RMSE error $\left(1.28{ }^{\circ} \mathrm{C}\right)$ compared to the other scenarios $\left(\mathrm{R}^{2}=0.67,0.69\right.$, and 0.76 for, respectively, a threshold of $100 \%, 75 \%$, and $25 \%$ ).

In this article, different types of MODIS/Terra land surface temperature products are used instead of a simulated MODIS image derived from the high-resolution Landsat 7 ETM+ thermal image used in Essa et al. [29] for Dublin city. Essa et al. [29] expected larger errors when the procedure would be applied to real MODIS data. The reason is due to the fact that real images have additional noise in the temperature data related to sensor registration. Note that the aggregation process used in 
Essa et al. [29] served to narrow down the dynamic range in both land surface temperature and NDVI, which is also discussed by Agam et al. [22].

\subsection{Evaluation Methods}

Three thermal downscaling methods (the original DisTrad, the improved DisTrad, and the uniform disaggregation (UniTrad)) are used to sharpen MODIS/Terra 5-min land surface temperature products (V4 and V5) to the different target resolutions 60, 90, 120, 240 and $480 \mathrm{~m}$. Evaluation is performed by comparing the sharpening results with the same resolutions of an aggregated time-coincident land surface temperature image of Landsat 7 ETM+ (band 6, low gain) using area averaging. More details on how land surface temperature for the Landsat ETM+ image was retrieved can be found in Essa et al. [26,29]. The Landsat 7 ETM+ image was acquired on 24 May 2001 (11:12 a.m.) with a $60 \mathrm{~m}$ resolution. The coefficient of determination $\left(\mathrm{R}^{2}\right)$ and the RMSE between the sharpened images and the observed Landsat 7 ETM+ temperature image were used as a measure for evaluation.

The evaluation of sharpened products from temporally averaged products of MODIS/Terra land surface temperature, such as the 1-Day MODIS/Terra product MOD11A1 and the 8-Day MODIS/Terra product MOD11A2 is not possible. This is due to the fact that those products are a temporal integration of two to eight images representing different points in time (day/night, hour) and meteorological conditions.

Evaluation of DisTrad for these products is assumed to be possible only if complementary evaluation is obtained from MODIS/Terra 5-min land surface product. It is also expected that both complementary MODIS land surface temperature products (averaged temporal images and the 5-min product) are collected within same season, using the same independent variable, e.g., impervious percentage image which is taken around the same date as the MODIS products. However, these assumptions have to take into consideration land-use/land-cover changes within the same season. The impervious percentage relationship with MODIS/Terra 1-Day or the 8-Day land surface temperatures can be used if the impervious percentage relationship with MODIS/Terra 5-min land surface temperatures is valid within the season. Downscaling this product category can be useful, especially for studies that aim at deriving relative urban temperature patterns rather than the absolute values from spaceborne remote sensing.

\section{Results and Discussion}

\subsection{MODIS and ETM Relationship}

Comparing the six observed MODIS/Terra land surface temperature products to the Landsat 7 ETM+ land surface temperature in the urban mask (Table 2), we notice that the MODIS/Terra mean land surface temperatures are considerably lower than the Landsat 7 ETM+ mean land surface temperature. The mean MODIS/terra 5-min land surface temperature is around $5{ }^{\circ} \mathrm{C}$ lower. Liu et al. [1] describe this as a systematic bias. Satellite-derived LST is generally a radiative product, delivering what is termed radiative or radiometric temperature [51]. Radiative temperature is closely related to the kinetic temperature, but influenced by surface properties (emissivity) and external radiation sources [52]. The radiance registered at the satellite sensor contaminated with different error sources can be generally categorized into three groups: (1) errors caused by terrain characteristics, e.g., relief, shadows, spatial arrangement and areal extent, materials (emissivity, heat capacity, etc.), (2) errors caused by the atmosphere and (3) errors caused by the sensor. Therefore, it is impossible to separate temperature from radiance sources of errors such as the emissivity without a priori knowledge of the thermal radiative properties of the surface [53]. This means that the accurate estimation of surface emissivity and description of other environmental factors at the pixel level is important for satellite-based models of the surface energy balance [54].

The bias to the "true" temperature can be induced by sensor measurement errors including random noise and systematic errors, which leads to variations in radiance at the satellite sensor [1]. 
Sensor thermal radiance measurements are dependent upon the width of the thermal band, which responds according to the biophysical and biochemical thermal conditions at the surface. Therefore, it will be difficult to extrapolate thermal radiance measurements from one sensor to another sensor or from one study area to another one. The wavelengths of the thermal bands for both MODIS and ETM have similar band widths (MODIS and Landsat 10.4-12 $\mu \mathrm{m}$ ), while the land-cover emissivities are wavelength dependent, the sensors can have different effective emissivities and hence create a bias for the brightness temperature [55]. Unfortunately, this error could not be excluded, although the band widths are similar, but the emissivities in urban areas are variable.

Guo and Moore [56] sharpened LST using the visible and near-infrared (VNIR) bands to identify topographic variations. LST can be predicted accurately for areas with varied topography and homogeneous land cover where the sun angle is the driving force for LST differences. However, topography is not a determining factor for flat urban areas such as Dublin City. Since the study area is nearly flat, shadow due to topography is minimal. Pixels containing shadows are present but are due to buildings. The small number of tall buildings combined with the midday image acquisition time, also minimizes these shadow effects.

In this study, the calculated systematic bias shows that MODIS/Terra 5-min, 1-Day, and 8-Day land surface temperatures (Figure 2) are, respectively, $5.23{ }^{\circ} \mathrm{C}, 9.85^{\circ} \mathrm{C}$, and $8.15^{\circ} \mathrm{C}$ (Table 2) lower than the Landsat 7 ETM+ land surface temperature mean value. Figure 3 shows the results of the correlation between MODIS/Terra land surface temperatures products against the observed aggregated Landsat 7 ETM+ image. The MODIS/Terra 5-min land surface temperature products show a higher correlation $\left(R^{2}\right)$ (Figure 3a) and lower RMS error than the other products (Figure 3b). MODIS/Terra 1-Day and 8-Day land surface temperature products show, as expected, a lower correlation than the 5-min products, but the differences are relatively small. The RMSE for the 1-Day product is higher than for the 8-Day product (Figure 3b). The reason is the fact that the 8-Day product averages images over a longer period. The 1-Day product covers a much shorter period. It is therefore likely that this product has a larger RMS error because of a higher probability of different meteorological conditions than during the Landsat 7 ETM+ acquisition. Hence, the MODIS/Terra versus Landsat 7 ETM+ correlations have smaller RMSE values for the 5-min products than the 1-Day products.

The slope (Figure 3c) shows the gradient of MODIS temperature values with the Landsat 7 ETM+ image. If the slope equals 1, MODIS and Landsat 7 ETM+ land surface temperature values are equal, hence have the same gradient. All product types of MODIS/Terra land surface temperatures have a similar slope of approximately 0.8 . Only the 1-Day (V4) product shows a lower slope than the average $(\sim 0.6)$, and this is possibly a result of the fact that the meteorological conditions during acquisition of the images used in aggregating the 1-Day product were more variable.

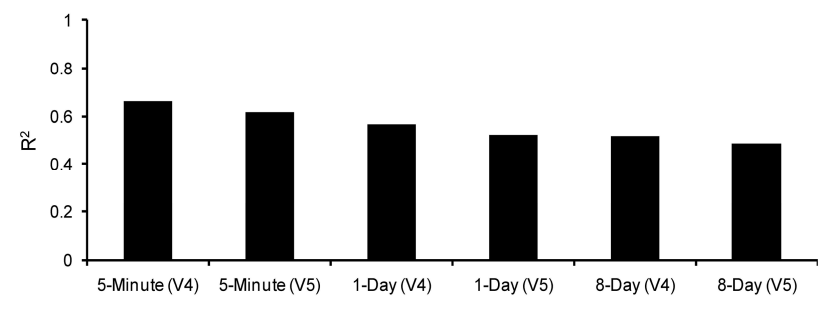

(a)

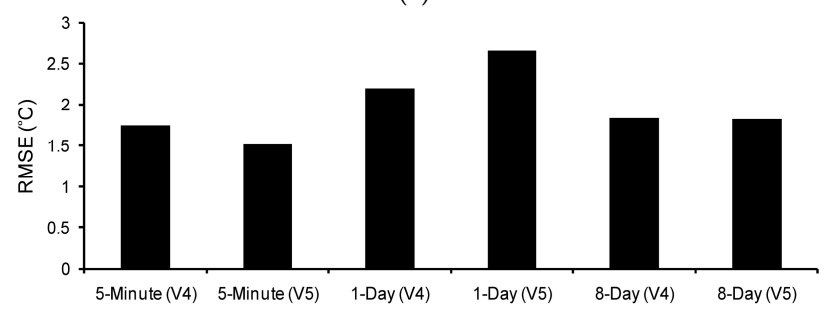

(b)

Figure 3. Cont. 


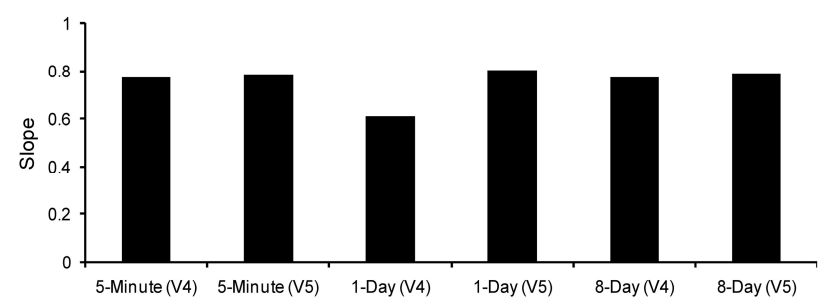

(c)

Figure 3. Relationship between MODIS/Terra land surface temperature products versus the aggregated observation of Landsat $7 \mathrm{ETM}+$ land surface temperature at $960 \mathrm{~m}$ resolutions for the urban mask. (a) coefficient of determination $\left(\mathrm{R}^{2}\right)$; (b) root mean square error (RMSE); and (c) slope of regression relationship.

\subsection{Impervious Percentage-MODIS/Terra Relationship}

The relationship between MODIS/Terra land surface temperature products and impervious percentage was studied at $960 \mathrm{~m}$ resolution. Figure 4 a shows the correlation between 5-min land surface temperature products (V4 and V5) and impervious percentage. Four different thresholds $(25 \%, 50 \%$, $75 \%$, and $100 \%$ of the most uniform pixels) within the urban mask are used for a sub-selection based on the coefficient of variance.

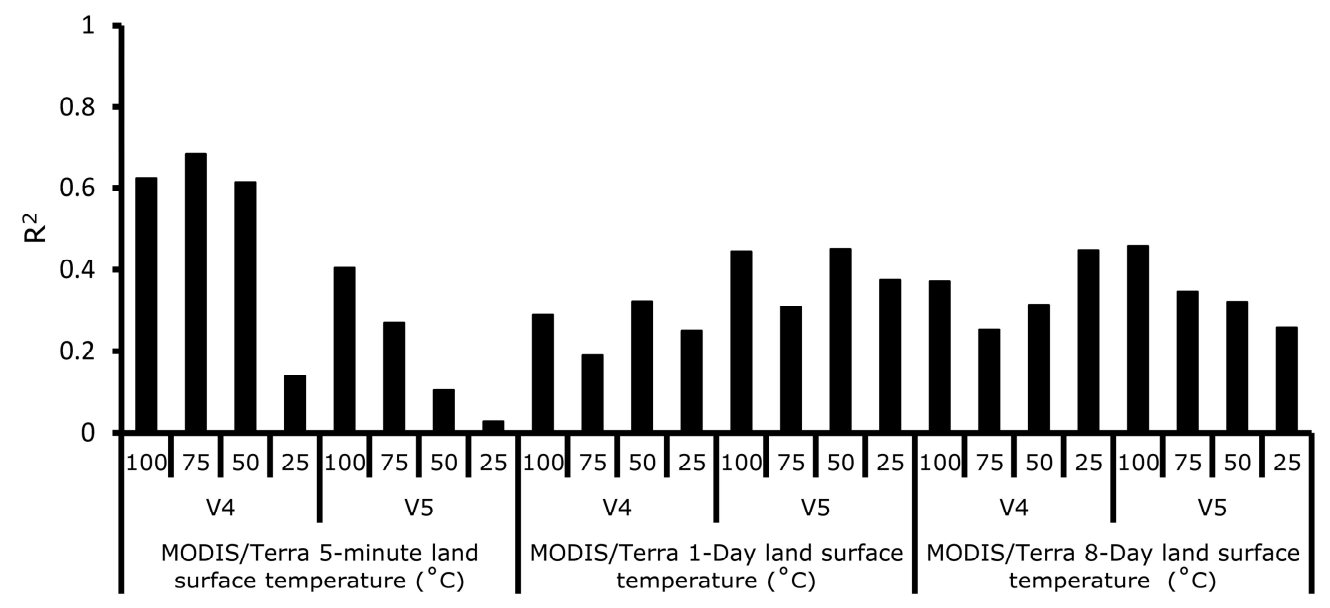

(a)

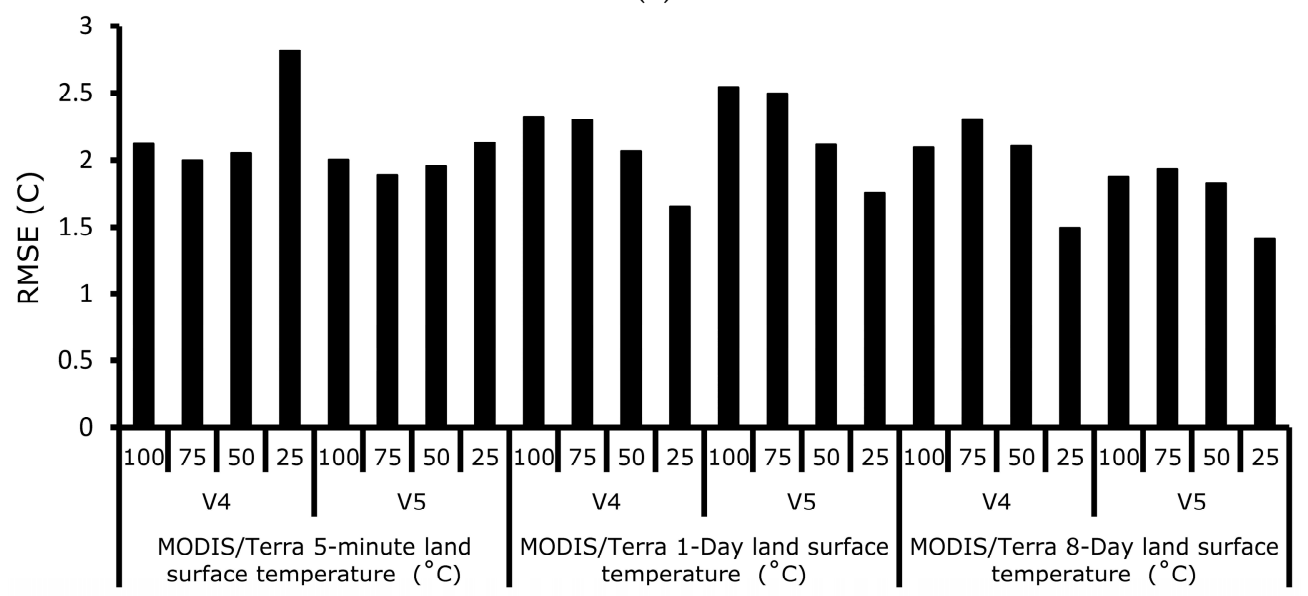

(b)

Figure 4. (a) Correlation $\left(\mathrm{R}^{2}\right)$ and (b) RMSE, between impervious percentage and MODIS/Terra land surface temperature at $960 \mathrm{~m}$ resolution, using different threshold pixel selections scenarios ( $25 \%, 50 \%$, $75 \%$ and $100 \%)$. 
The best correlation between impervious percentage and the 5-min land surface temperature was obtained for the scenario where the full range of pixels and impervious percentage data $(75-100 \%$, and $100 \%$ for V4 and V5 respectively) is used in the regression analysis. This scenario results in a $\mathrm{R}^{2}$ of 0.62 and 0.40 , and an RMSE (Figure $4 \mathrm{~b}$ ) of $2.06{ }^{\circ} \mathrm{C}$ and $2.00^{\circ} \mathrm{C}$, respectively. The sharpening scenario using a threshold value of $25 \%$ shows the worst correlation, with $\mathrm{R}^{2}=0.14$ and 0.03 for V4 and V5 respectively. V5 shows in general lower correlation than V4. V5 has considerably smaller range than V4 (Table 2), although both are time coinciding, but the refinements and the quality control filters of the V5 algorithm decreases the surface temperature range, consequently lowering the correlation with the impervious percentage.

The relationship between MODIS/Terra land surface temperature product (V4) and impervious percentage (Figure 5) was investigated using linear and nonlinear models (e.g., exponential). The results show that a first order linear model has a higher correlation $\left(\mathrm{R}^{2}=0.62\right)$ and a smaller error $\left(\right.$ RMSE $\left.=2.12{ }^{\circ} \mathrm{C}\right)$ than an exponential model $\left(\mathrm{R}^{2}=0.27\right.$ and an RMSE $\left.=3.00^{\circ} \mathrm{C}\right)$. The exponential fit is more influenced by the upper and lower tails (outliers) of the impervious percentage distribution than the linear model.

The highest correlation between impervious percentage and the MODIS/Terra 1-Day land surface temperature products was obtained for the $50 \%$ and $100 \%$ scenarios. We obtain, respectively, an $\mathrm{R}^{2}$ of 0.32 and 0.29 for V4 and an $\mathrm{R}^{2}$ of 0.45 and 0.44 for V5 (Figure 4a) and an RMSE of $2.06^{\circ} \mathrm{C}$ and $2.32{ }^{\circ} \mathrm{C}$ for V4 and $2.11^{\circ} \mathrm{C}$ and $2.54{ }^{\circ} \mathrm{C}$ for V5 (Figure $4 \mathrm{~b}$ ).

The highest correlation between impervious percentage and the MODIS/Terra 8-Day land surface temperature product was obtained when $25 \%$ and $100 \%$ of impervious percentage data was used in the regression analysis with V4 and V5. These scenarios result in a $\mathrm{R}^{2}$ of 0.38 and 0.37 for $\mathrm{V} 4$ and $\mathrm{R}^{2}$ of 0.26 and 0.46 for V5 (Figure 4a), and an RMSE error of $1.50{ }^{\circ} \mathrm{C}$ and $2.09^{\circ} \mathrm{C}$ for V4 and $1.41{ }^{\circ} \mathrm{C}$ and $1.88^{\circ} \mathrm{C}$ for V5 (Figure $4 \mathrm{~b}$ ).

To conclude, the best threshold is difficult to select, due to the fact that MODIS land surface temperature pixels are dependent on acquisition time, collection method, meteorological conditions, etc. Generally, the best correlation was obtained when all pixels of impervious percentage and the V4 product are used. The linear regression model best suits the urban area of Dublin in comparison with the exponential model (Figure 5). Based on this evaluation, the scenario that uses full cover of impervious percentage pixels (100\%) is further used with a first order linear model to evaluate DisTrad downscaling. MODIS/Terra land surface temperature of 1-Day and 8-Day will not be downscaled with DisTrad.

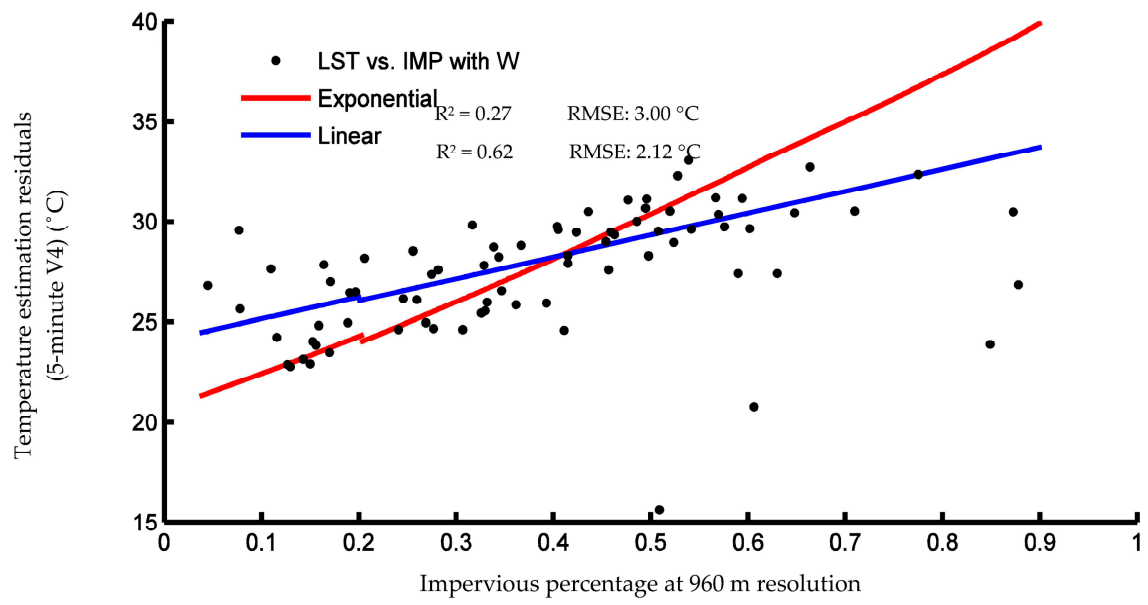

Figure 5. Linear (blue line) and an exponential (red line) fit for MODIS/Terra land surface temperature product (V4) with $100 \%$ of impervious percentage pixels. 
The technical steps of downscaling were summarized in Figure 6. The following regression equations were obtained for downscaling MODIS/Terra 5-min land surface temperature products (V4 and V5):

$$
\begin{aligned}
& \text { MOD_LST }\left(5 M \_V 4\right)_{960}=9.827+24.08 \times \mathrm{I}_{960} \\
& \text { MOD_LST(5M_V5) })_{960}=9.770+24.09 \times \mathrm{I}_{960}
\end{aligned}
$$

MOD_LST(5M_V4) $)_{960}$ is the estimated land surface temperature using the 5-min V4 product, while MOD_LST(5M_V5) ${ }_{960}$ is the estimated land surface temperature using the 5-min V5 product.

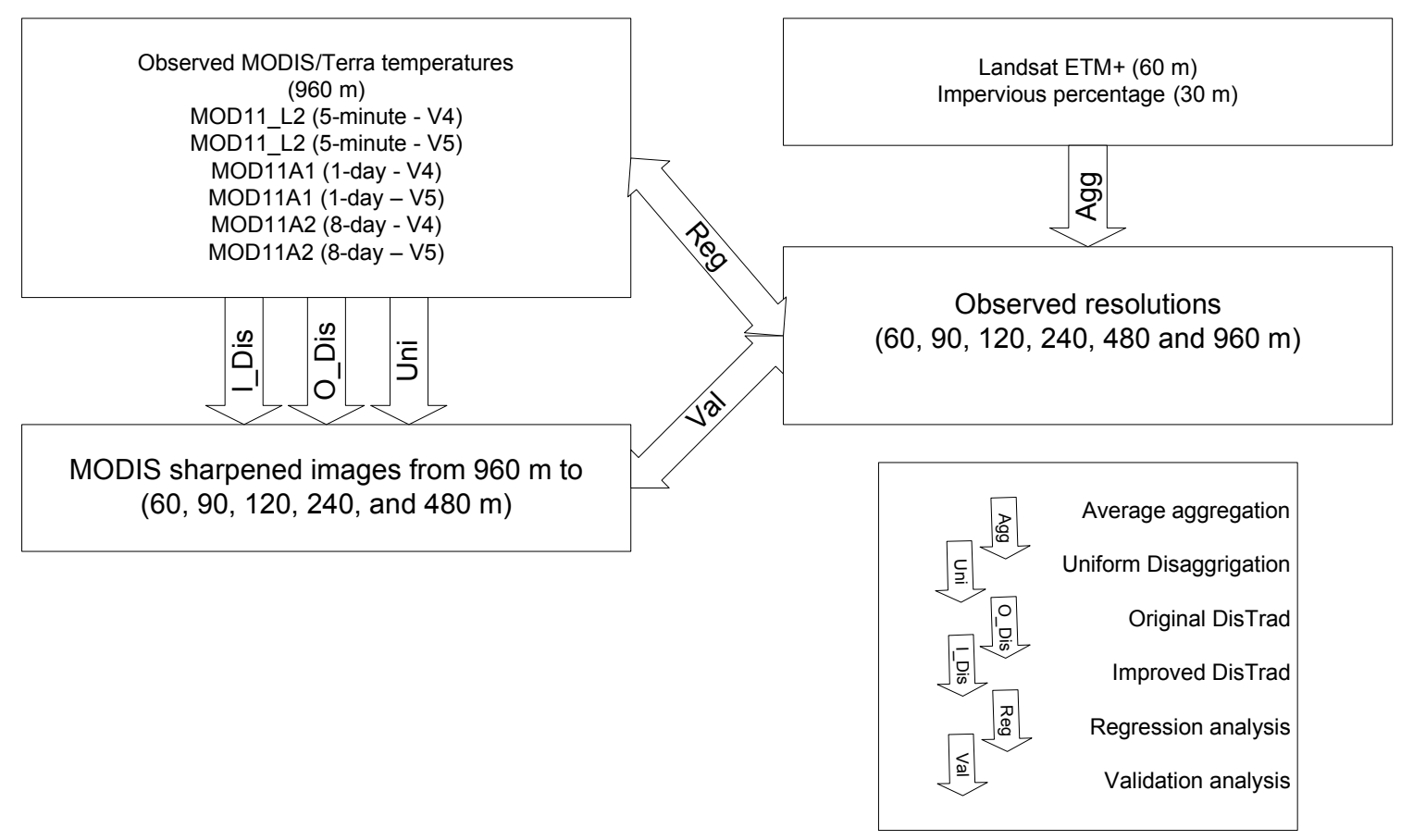

Figure 6. Schematic diagram presenting an overview of the aggregation, re-sampling, downscaling, regression analysis, and validation, at different resolutions (60, 90, 120, 240, 480 and $960 \mathrm{~m})$.

\subsection{Parameterization of the Temperature Estimation Residuals}

Based on the regression analysis within the urban mask, an exponential relationship was found between temperature estimation residuals and impervious percentage (Figure 7). The exponential model is calculated from the original DisTrad method and the impervious percentage. The temperature estimation residuals show a similar relationship for both V4 (Figure 7a) and V5 (Figure 7b) images. The resulting exponential model equations are given in Equations (8) and (9) for V4 and V5, respectively:

$$
\begin{gathered}
\Delta \overline{\mathrm{T}}(\mathrm{V} 4)_{960}=4.295 \times \exp \left(-0.03295 \times \mathrm{I}_{960}\right)-12.39 \times \exp \left(-2.263 \times \mathrm{I}_{960}\right) \\
\Delta \overline{\mathrm{T}}(\mathrm{V} 5)_{960}=2.516 \times \exp \left(0.4372 \times \mathrm{I}_{960}\right)-11.88 \times \exp \left(-3.361 \times \mathrm{I}_{960}\right)
\end{gathered}
$$

The exponential models show high correlations $\left(R^{2}=0.9985\right.$ and 0.9652$)$ and small RMSE $\left(0.12{ }^{\circ} \mathrm{C}\right.$ and $0.44{ }^{\circ} \mathrm{C}$ ) for V4 and V5 products, respectively. In this analysis, $2.5 \%$ of the tails of the range in the input land surface temperature maps were excluded in order to analyse $95 \%$ of the dynamic range. The good correlations justify an improved parameterization of the residuals in DisTrad based on an exponential relationship with impervious percentage. 


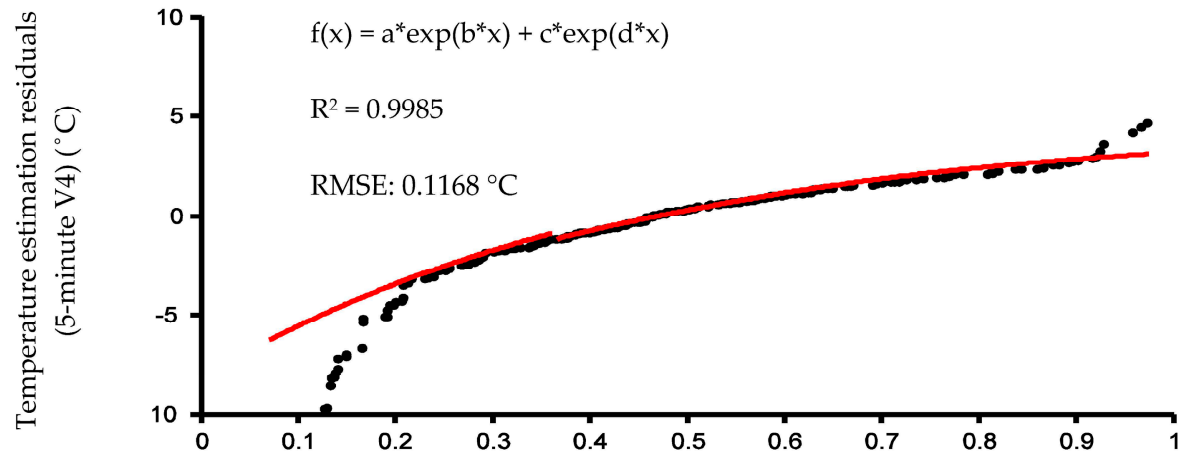

(a) Impervious percentage at $960 \mathrm{~m}$ resolution

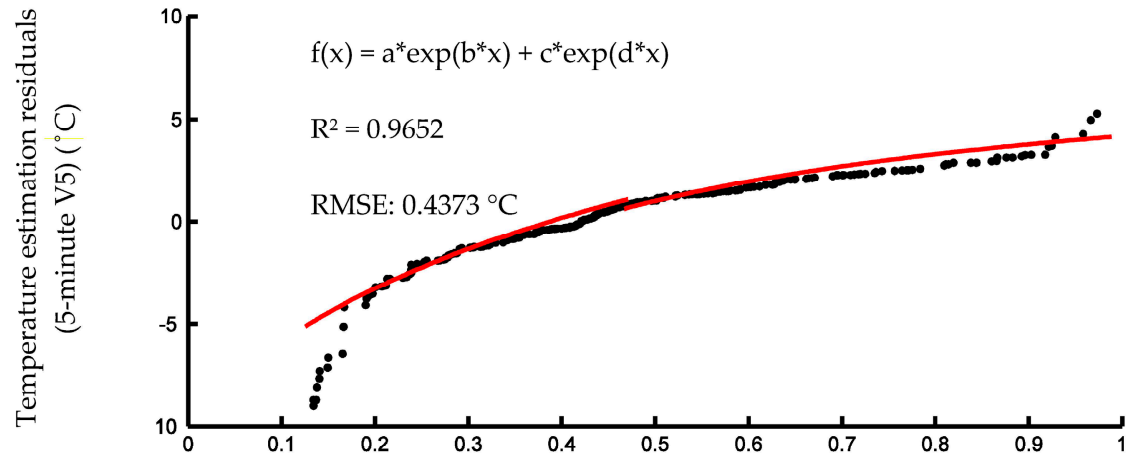

(b) Impervious percentage at $960 \mathrm{~m}$ resolution

Figure 7. Exponential fit model between impervious percentage index and temperature estimation residuals calculated using the original DisTrad based on impervious percentage [26,29] applied to MODIS 5-min land surface temperature products (a) V4 and (b) V5 at low resolution of $960 \mathrm{~m}$.

Although DisTrad was based on a linear correlation between impervious percentage and LST, the resulting temperature estimation residuals show at low resolution $(960 \mathrm{~m})$ a nonlinear exponential relationship with the impervious percentage. This appears to be mainly due to the fact that DisTrad was applied within the irregularly shaped urban mask of Dublin city. The mask is also characterized by 'holes' with other land covers (Figure 1) [57]. During upscaling to the different resolutions (from 30 to $960 \mathrm{~m}$ resolution), this introduces the problem of a changing mean value of impervious percentage and a changing area of the urban mask after aggregation. Consequently, temperature estimation residuals deviate at the lower tails of the impervious percentage distribution, which is caused by mixed pixels at the boundary of the urban mask. This is strongest for the aggregation at $960 \mathrm{~m}$ resolution and reduces to the finer resolutions. This means that the relationship between the residuals and $\mathrm{I} \%$ is scale dependent. The middle part of the exponential curve for the $960 \mathrm{~m}$ resolution regression shows a more persistent and gradual increase, which is similar to the original linear relationship, resembling urban blocks with a full cover of impervious percentage. Overall, the exponential regression fits the residuals slightly better than the original DisTrad temperature estimation residuals when downscaling low resolution imagery such as MODIS resolution (960 m). However, when downscaling a Landsat 7 ETM+ land surface temperature image from higher resolution $(60 \mathrm{~m})$ to $30 \mathrm{~m}$ in Essa et al. [26], results were similar for the linear and exponential regression models when the improved disaggregation method was applied (Figure $8 \mathrm{~b}$ ). Hence, the suggested improvement to the DisTrad approach using an exponential relationship between temperature estimation residuals and impervious percentage is applicable to kilometer scale MODIS thermal resolution within the urban mask, and it is expected to yield similar results with other low thermal resolution sensors, e.g., NOAA AVHRR. However, for other thermal imagery, with a higher resolution such as Landsat 5 TM, Landsat 7 ETM+, and ASTER, the use of an exponential relationship between the temperature estimation residuals and impervious percentage does not improve the downscaling. 


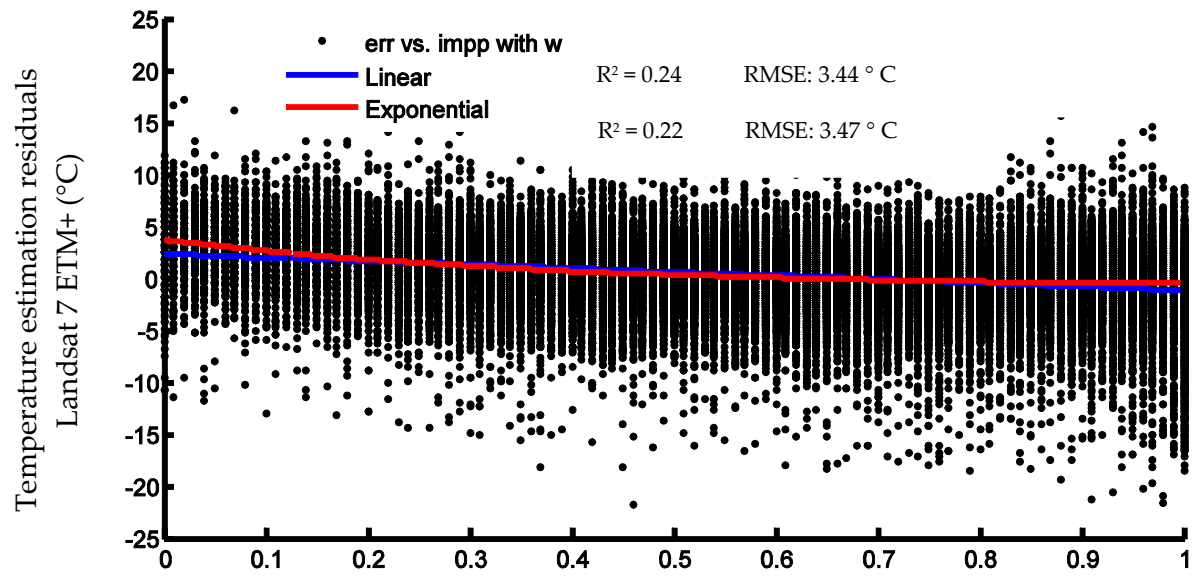

(a) Impervious percentage at $60 \mathrm{~m}$ resolution

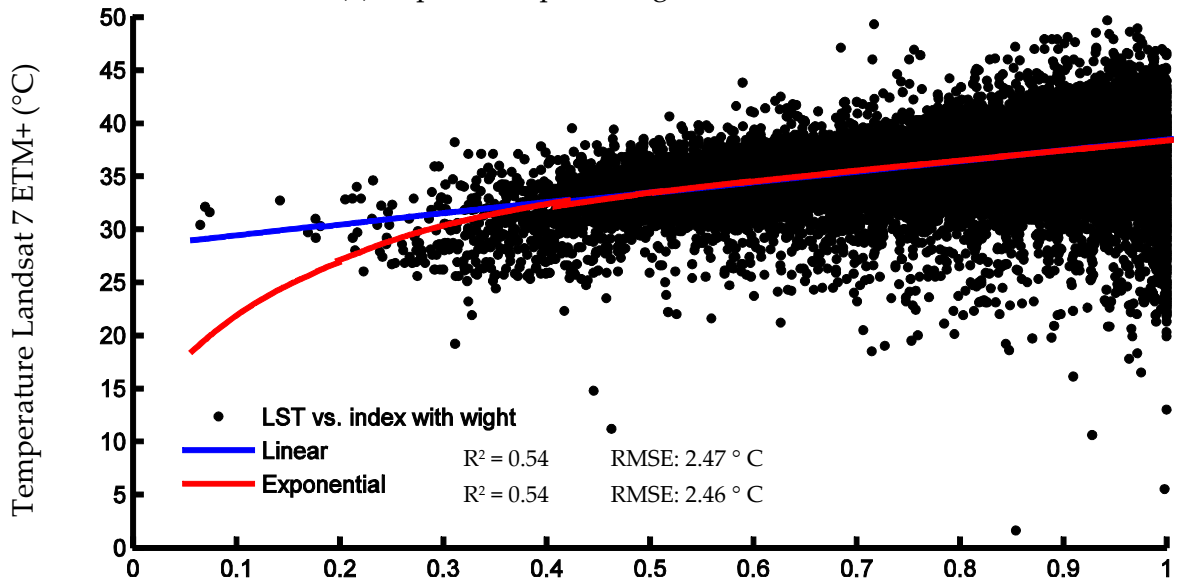

(b) Impervious percentage at $60 \mathrm{~m}$ resolution

Figure 8. Linear (blue line) and exponential (red line) fits between temperature estimation residuals of Landsat 7 ETM+ and impervious percentage. (a) original DisTrad function; and (b) improved temperature estimation residuals' disaggregation method.

As it is expected, the adapted version of DisTrad did not yield similar results when applied to temporally integrated MODIS/Terra land surface temperature products, such as 1-Day MODIS/Terra product "MOD11A1" or 8-Day MODIS/Terra product "MOD11A2". In addition, 1-Day MODIS/Terra products V4 and V5 yielded low correlation $\mathrm{R}^{2}(0.13$ and 0.11$)$ and higher RMSE $\left(2.13^{\circ} \mathrm{C}\right.$ and $\left.2.85^{\circ} \mathrm{C}\right)$ for V4 and V5, respectively. Furthermore, 8-Day MODIS/Terra products V4 and V5 yielded also low correlation $\mathrm{R}^{2}(0.13$ and 0.11$)$ and higher RMSE $\left(2.13{ }^{\circ} \mathrm{C}\right.$ and $\left.2.85{ }^{\circ} \mathrm{C}\right)$ for V4 and V5, respectively. These products are a combination of several 5-min land surface temperature products, taken at different points in time (day, hour); consequently, the impervious percentage pixels fit poorly with temperature estimation residuals because of meteorological changes (wetness) of the impervious surfaces.

\subsection{Evaluation of Downscaled Products}

The original DisTrad [29], the improved DisTrad in this article and the UniTrad methods were applied for downscaling MODIS/Terra 5-min V4 and V5 products to the different target resolutions. The regression fit parameters given in Equations (6) and (7) are used, respectively, in the original DisTrad to downscale MODIS/Terra 5-min V4 and V5 products. The improved DisTrad was used in downscaling the same products using the exponential relationship between the temperature estimation residuals and impervious percentage with the regression parameters given in Equations (8) and (9) and applied to each of the target resolutions. 
The downscaling results are compared with a time-coincident land surface temperature image derived from Landsat $7 \mathrm{ETM}+$ for the urban mask using correlation analysis based on linear regression. The coefficient of determination $\left(R^{2}\right)$ and RMSE are shown in Figure $9 a, b$, respectively. The improved DisTrad shows higher correlations and lower RMSE than the original DisTrad and UniTrad methods at all resolutions of V4 when compared with the observed Landsat 7 ETM+ land surface temperature image. The improved DisTrad approach also shows a similar trend for the $\mathrm{R}^{2}$ results from the V5 product. The RMSE, however, was slightly higher than the original DisTrad for the V4 product at resolutions from $60 \mathrm{~m}$ to $240 \mathrm{~m}$, due to the fact that the V5 product has a smaller surface temperature range than V4 (Table 2), which resulted from refinement and quality control procedure of V5.

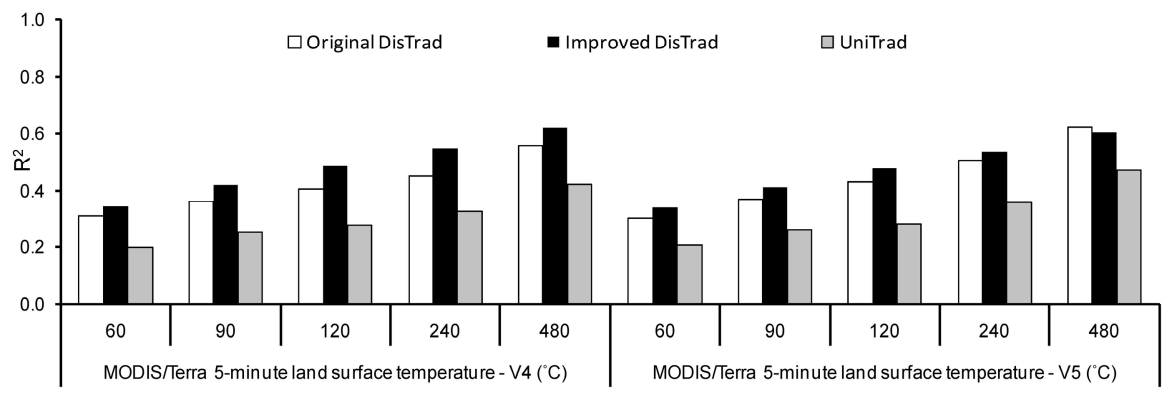

(a)

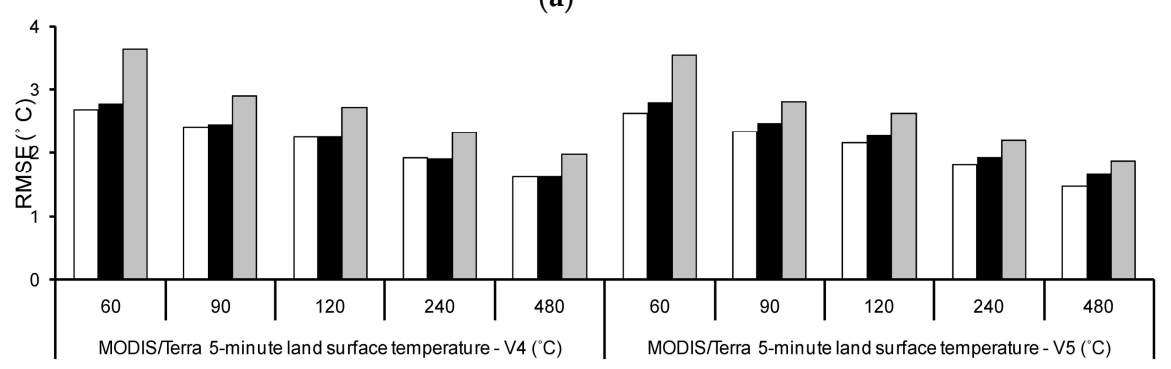

(b)

Figure 9. (a) coefficient of determination $\left(R^{2}\right)$; and (b) root mean square error (RMSE) between downscaled products of MODIS 5-min land surface temperature (V4 and V5) and observed Landsat 7 ETM+ land surface temperature at different resolutions $(60,90,120,240$, and $480 \mathrm{~m})$.

In comparison with the widely used RMSE, the Mean Absolute Error (MAE) has the advantage of being less sensitive to the distribution of the errors and the number of data points $[22,29,58]$. MAE was used to assess the magnitude of error divergence of the sharpened products using the improved DisTrad, the original DisTrad, and the UniTrad from the observed Landsat 7 ETM+ land surface temperature image (Figure 10). The improved DisTrad method shows a systematic decrease in MAE with about $0.26{ }^{\circ} \mathrm{C}$ and with $0.02{ }^{\circ} \mathrm{C}$ averaged along all scales for V4 and V5, respectively.

To conclude, the improved DisTrad method shows lower errors than the original DisTrad implementation in downscaling MODIS/Terra 5-min products V4 and V5 over urban areas. Parameterization of temperature estimation residuals was essential for improvement of the DisTrad results. The major refinement (see Section 1) of the V5 collection method reduces the surface temperature range. Table 2 shows that V 5 contains therefore much warmer pixels based on the value range magnitude $\left(10.96^{\circ} \mathrm{C}\right)$. On the other hand, V4 has a wider range $\left(18.16^{\circ} \mathrm{C}\right)$ of land surface temperatures (Table 2), which allows a better differentiation of urban surface types. Downscaling image temperature products is an image based procedure, and it can be expected that image to image variation may occur on an hourly timescale. Consequently, the downscaling equation would have to be determined for each image. It is also recommended that MODIS land surface temperature products with full image coverage are essential for downscaling MODIS/Terra land surface temperature products. 


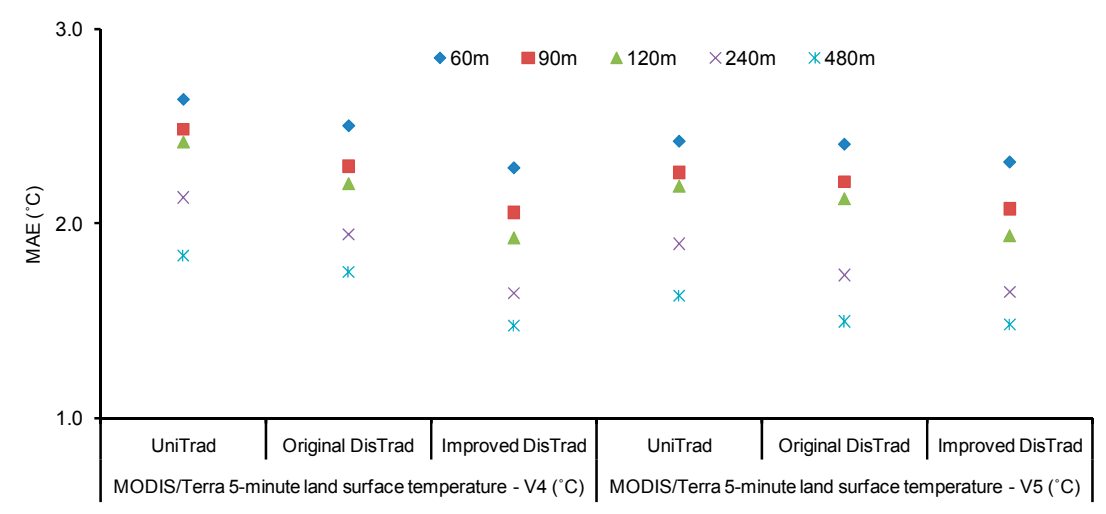

Figure 10. Mean Absolute Error (MAE) between downscaled products from MODIS/Terra 5-min land surface temperature (V4 and V5) using UniTrad, original DisTrad, and improved DisTrad, and observed Landsat 7 ETM+ land surface temperature at different resolutions $(60,90,120,240$, and $480 \mathrm{~m})$.

Figure 11 shows the systematic bias of the mean temperature between the Landsat 7 ETM+ land surface temperature image and the sharpened land surface temperature product of the downscaled MODIS $\backslash$ Terra land surface temperature (V4 and V5) using the three downscaling methods applied to all target resolutions. The improved DisTrad method shows the smallest systematic divergence $\left(4.46{ }^{\circ} \mathrm{C}\right)$ from the observed Landsat 7 ETM+ land surface temperature image, while the original DisTrad $\left(5.40^{\circ} \mathrm{C}\right)$ and the UniTrad method $\left(6.17^{\circ} \mathrm{C}\right)$ show the highest biases. A smaller systematic bias is related to an average image value closer to the average Landsat ETM+ land surface temperature image, and this results from a better estimation of land surface temperatures.

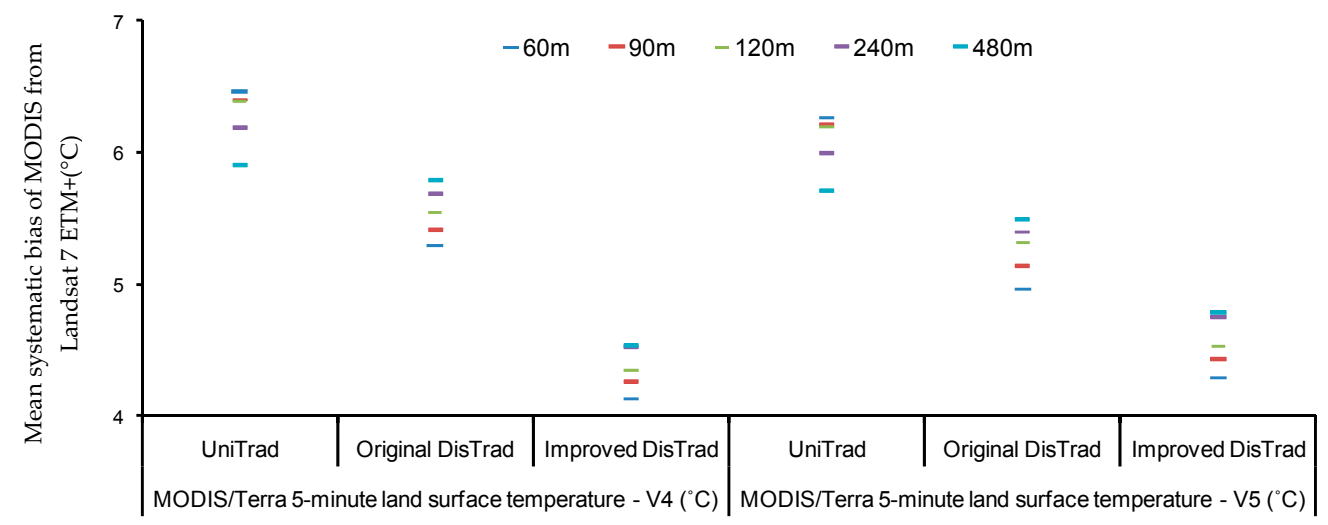

Figure 11. Mean temperature systematic bias of the downscaled products from MODIS $\backslash$ Terra 5-min land surface temperature (V4 and V5) using the UniTrad, original DisTrad, and Improved DisTrad compared to the observed Landsat 7 ETM+ land surface temperature.

Figure 12 shows the linear regressions between the downscaled land surface temperature images and the (aggregated) Landsat 7 ETM+ land surface temperatures at 60, 90, 120, 240, and $480 \mathrm{~m}$ resolution. The gap between the regression lines and the bisector demonstrates the systematic bias between the downscaled products of MODIS/Terra 5-min land surface temperature with Landsat 7 ETM+ results. All methods show a similar downscaled temperature at about $30^{\circ} \mathrm{C}$, which corresponds to the Landsat $7 \mathrm{ETM}+$ mean surface temperature $\left(\sim 33^{\circ} \mathrm{C}\right.$ at $60 \mathrm{~m}$ resolution). Hence, at this mean Landsat 7 ETM+ temperature, all methods show the same systematic bias, while, at lower and higher temperatures, the bias varies. The improved DisTrad procedure shows clearly that it has an almost constant bias over the whole range of temperatures and that this bias is smaller than for the original DisTrad and UniTrad implementations. The original DisTrad and UniTrad methods overestimate the land surface temperatures in urban areas with a lower temperature, while they underestimate 
the land surface temperatures in areas with a higher value than the mean Landsat 7 ETM+ land surface temperature.
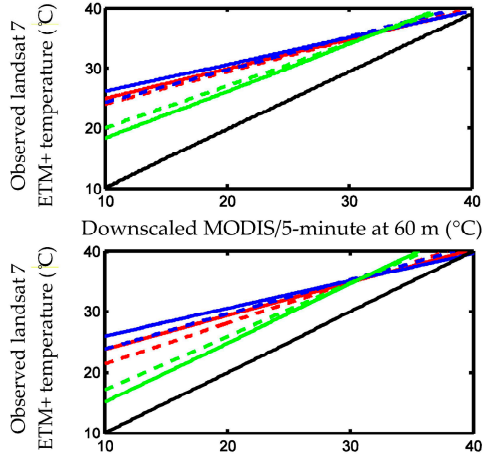

Downscaled MODIS/5-minute at $120 \mathrm{~m}\left({ }^{\circ} \mathrm{C}\right)$

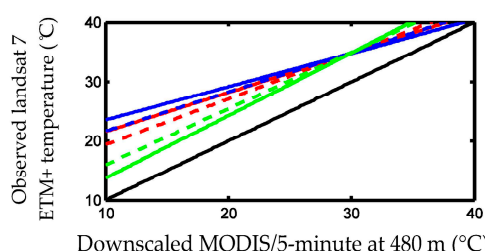

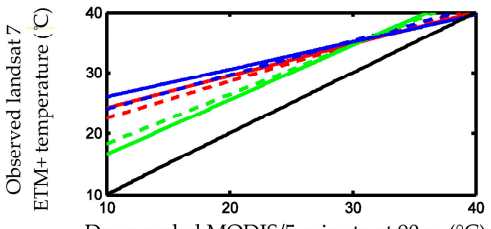
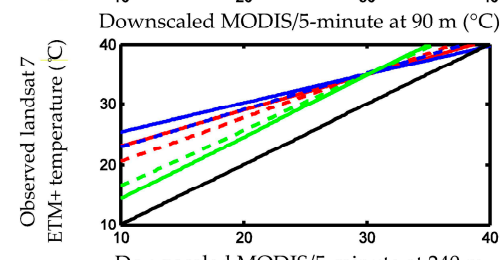

Downscaled MODIS/5-minute at $240 \mathrm{~m}$

$\left({ }^{\circ} \mathrm{C}\right)$

Original DisTrad (V4)

- - - Original DisTrad (V5)

- UniTrad (V4)

- - - UniTrad (V5)

- Improved DisTrad (V4)

- - - Improved DisTrad (V5)

1:1

Figure 12. Linear regressions of the downscaled MODIS 5-Min land surface temperature products (V4 and V5) using the improved DisTrad, the original DisTrad, and UniTrad methods with the observed Landsat 7 ETM+ land surface temperature image at different resolutions (e.g., 60, 90, 120, 240, and $480 \mathrm{~m}$ ). The dashed line represents V5 and the sold line represents V4.

The level of agreement between the observed and sharpened temperatures was evaluated by comparing the land surface temperature image histograms, using the normal distribution model (Figure 13a). The 2.5\% tails from the range of the input land surface temperature maps were excluded in order to analyse the $95 \%$ range.

The improved DisTrad land surface temperature mean values of V4 and V5 are much closer to the mean value of the observed Landsat ETM+ land surface temperature image than the original DisTrad and UniTrad land surface temperature mean values. However, the improved DisTrad approach shows a smaller land surface temperature range. Both effects are a result of the fact that each downscaling method broadens or narrows the land surface temperature range, as well as increases or decreases the land surface temperature mean value differently. The differences can be summarized by the three following points (Figure 13a): (1) for UniTrad, the method applies a uniform disaggregation of the temperature minimum and maximum values, hence keeps a wider range corresponding to the wide range of the Landsat 7 ETM+ land surface temperature image. The UniTrad distribution for V5 shows a higher peak than V4 due to the fact that warmer pixels are collected in V5, which results in less outliers; (2) for the original DisTrad, the method adds back the temperature estimation residuals (Equation (4)) to the estimated land surface temperatures (Equation (3)), which increases the range. This is due to the fact that the temperature estimation residuals represent the differences from the estimated land surface temperature at the low resolution. Hence, the latter is very close to the original MODIS/Terra land surface temperature values. Consequently, adding back the temperature estimation residuals (Equation (6)) keeps the land surface temperature range similar to UniTrad but increases the land surface temperature mean value because of an increase of estimated values resulting from the linear regression estimation. Hence, the mean of the distribution is closer to the corresponding mean of the Landsat 7 ETM+ land surface temperature image than UniTrad. V5 and V4 show similar maxima in the distribution at the higher resolutions (60-120 m), while V5 shows higher peaks for 240 and $480 \mathrm{~m}$ resolution, due to the fact that, at these resolutions, V5 has less outliers; (3) for the 
improved DisTrad approach, the downscaled products of land surface temperature are based on functional regressions for the estimation of land surface temperature (Equations (6) and (7) for V4 and V5, respectively) and temperature estimation residuals (Equation (8) and 4.9 for V4 and V5, respectively). The regression functions are eliminating the outliers, which causes a smaller range and higher maximum in the distribution than the original DisTrad and UniTrad results. The improved DisTrad of V4 shows a higher maximum than for V5 at all resolutions, different for what was found for the original DisTrad and UniTrad, due to the fact that V4 has a wider range, which results in a higher temperature peak.

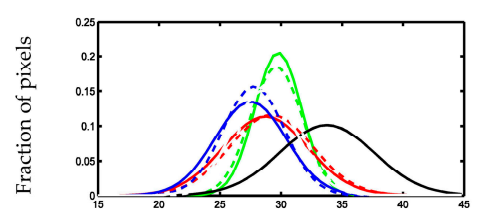

Distribution of downscaled product at $60 \mathrm{~m}\left({ }^{\circ} \mathrm{C}\right)$

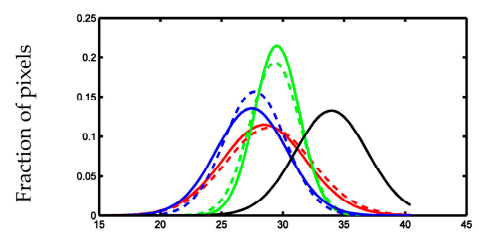

Distribution of downscaled product at $90 \mathrm{~m}\left({ }^{\circ} \mathrm{C}\right)$

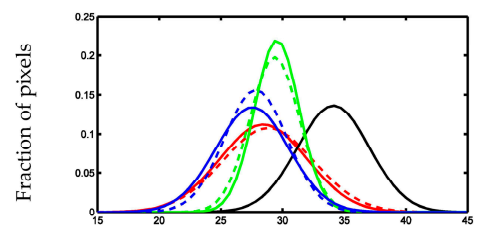

Distribution of downscaled product at $120 \mathrm{~m}\left({ }^{\circ} \mathrm{C}\right)$

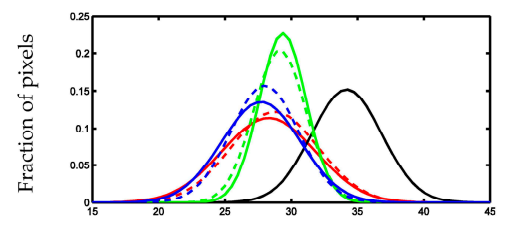

Distribution of downscaled product at $240 \mathrm{~m}\left({ }^{\circ} \mathrm{C}\right)$

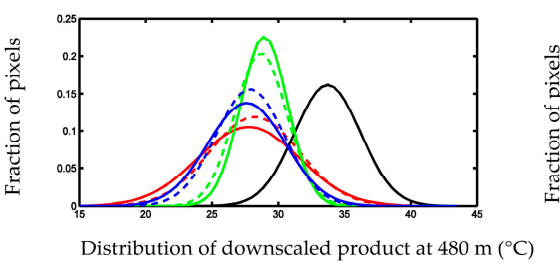

(a) Normal distribution

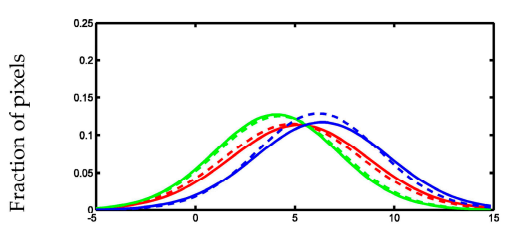

Error at $60 \mathrm{~m}\left({ }^{\circ} \mathrm{C}\right)$

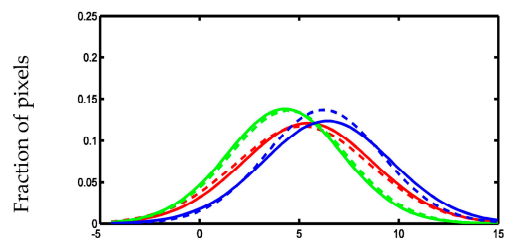

Error at $90 \mathrm{~m}\left({ }^{\circ} \mathrm{C}\right)$

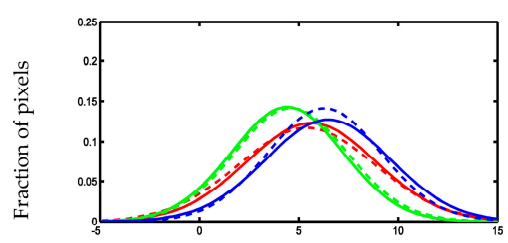

Error at $120 \mathrm{~m}\left({ }^{\circ} \mathrm{C}\right)$

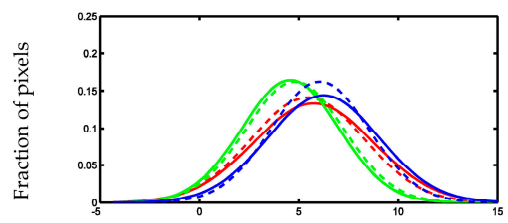

Error at $240 \mathrm{~m}\left({ }^{\circ} \mathrm{C}\right)$

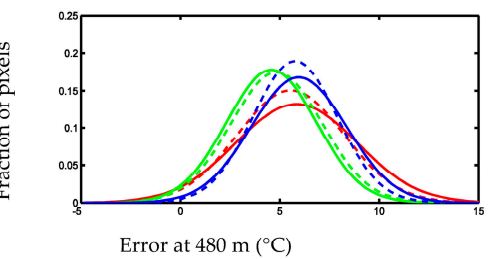

(b) Error distribution

$$
\begin{array}{ll}
\hline \text { - } & \text { Original DisTrad (V4) } \\
- & \text { Original DisTrad (V5) } \\
\hline--- & \text { UniTrad (V4) } \\
\hline & \text { UniTrad (V5) } \\
\hline--- & \text { Improved DisTrad (V4) } \\
\text { Improved DisTrad (V5) }
\end{array}
$$

Figure 13. The left side (a) shows the normal distribution of the observed and sharpened products using the improved DisTrad (green), the original DisTrad (red), and UniTrad (blue) land surface temperatures for versions V4 (solid) and V5 (dotted). The right side (b) shows the error distribution, resulting from subtracting the sharpened products from the observed temperatures. The analyses are presented for different resolutions (e.g., 60, 90, 120, 240, and $480 \mathrm{~m}$ ).

Figure 13b shows the normal distribution of the bias, which is estimated by subtracting the downscaled results derived from the improved DisTrad, and the original DisTrad and UniTrad methods 
from the observed Landsat 7 ETM+ temperature images. The improved DisTrad result shows the smallest deviation from zero, along all resolutions. UniTrad of the V5 land surface temperature product shows a higher maximum than the improved DisTrad method, but was not closer to the improved DisTrad method at $480 \mathrm{~m}$ resolution. The reason is the fact that V5 land surface temperatures have a smaller range.

Finally, Figure 14 visualizes the spatial patterns of the LST data, downscaled at different spatial resolutions using the improved DisTrad approach. As a reference, the observed Landsat 7 ETM+ LST (acquired on 24 May 2001) is also shown, at the original $60 \mathrm{~m}$ resolution as well as aggregated at the different spatial resolutions. The LST values in all maps range from 20 to $45^{\circ} \mathrm{C}$. The improved DisTrad, downscaled the MODIS LST data effectively and enhanced the spatial resolution while largely preserving the characteristics and spatial patterns of the observed LST. Exceptions are the coastal pixels, which are showing larger deviations, as the adopted residual parameterization does not capture the limited number of low LST values. As demonstrated earlier in Figures 10-13, errors increase with increasing resolution. As a result of the residual parameterization, the improved DisTrad results show no "boxy effect" anomalies like those commonly occurring in original DisTrad and UniTrad downscaled images.

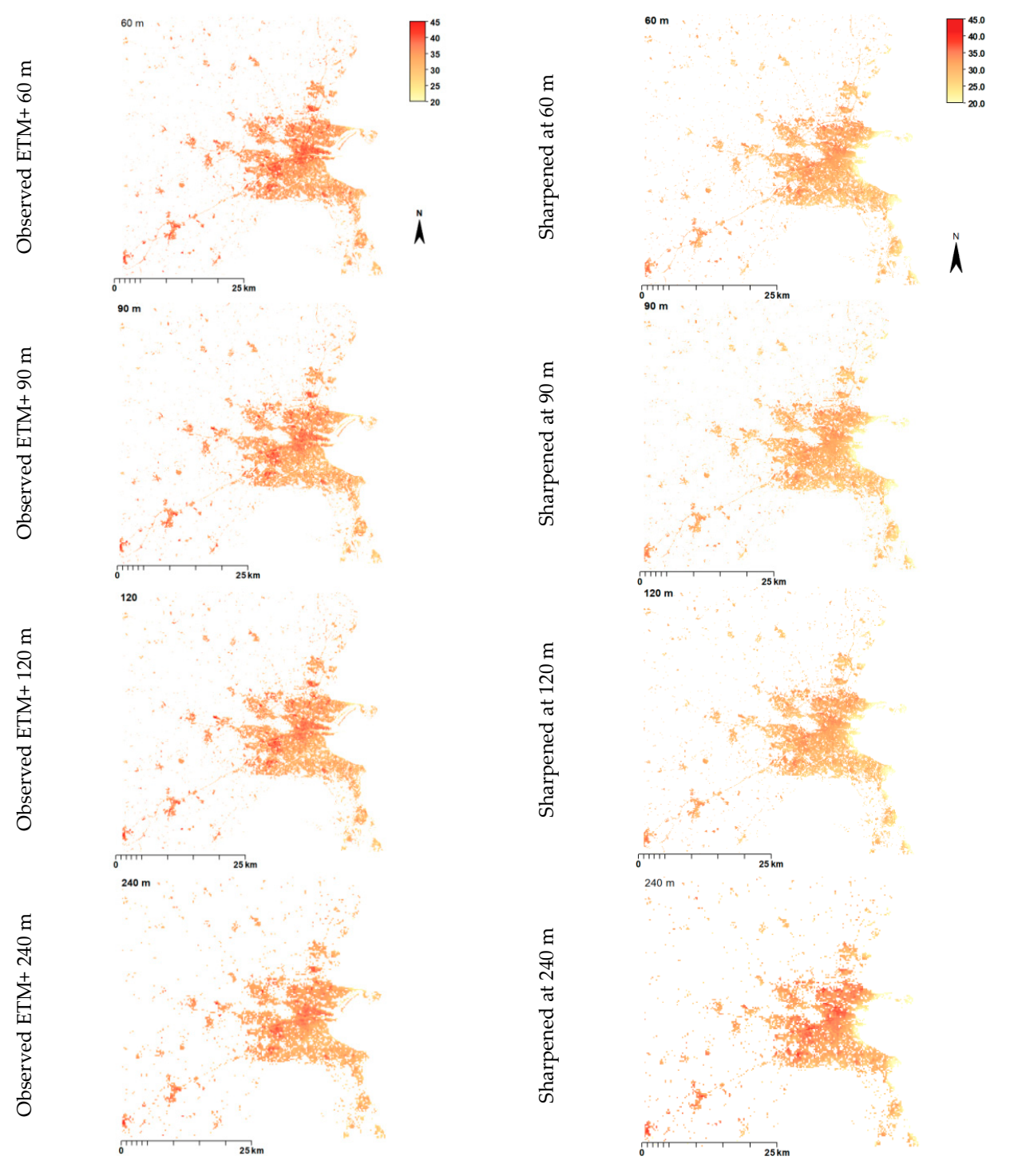

Figure 14. Cont. 

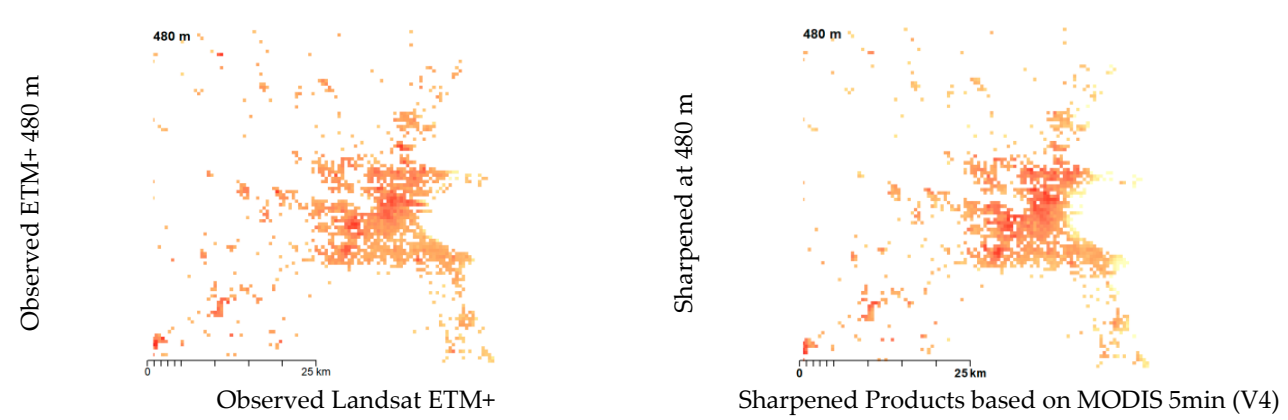

Figure 14. The left side maps are the observed land surface temperature in degrees Celsius derived from Landsat ETM+ band 6 (acquisition date 24 May 2001) at different resolution (60 to $480 \mathrm{~m}$ ). The right side maps are the sharpened images at the different spatial resolutions, obtained by using the improved DisTrad methodology to downscale the MOD11_L2 (5-min-V4) 960 m resolution image.

\section{Conclusions}

In previous studies [26,29], improvement of land surface temperature estimation over urban areas was evaluated using the relationship between land surface temperature and impervious percentage. In this article, further improvements were tested by evaluating the relationship between the temperature estimation residuals from land surface temperature and impervious percentage relationship with the impervious percentage. In the original DisTrad downscaling method, temperature estimation residuals at low resolution are disaggregated using a simple resampling method, which results in a poor temperature estimation at high resolution, especially in heterogeneous environments like urban areas. Transforming the temperature estimation residuals from the low resolution, which are indicative for the dominant thermal processes at the kilometer resolution of MODIS, to higher resolutions is found to introduce land surface temperature estimation errors.

The original DisTrad downscaling algorithm was revised and improved in an application for the city of Dublin. A more robust technique was demonstrated to improve the original DisTrad method for urban environments at a low resolution like MODIS (960 m).

The impervious percentage was found to be highly correlated with temperature estimation residuals using the exponential regression fit $\left(R^{2}=0.9985\right.$ and 0.9949 with a small root mean square error (RMSE) of 0.12 and 0.44 for the MODIS/Terra 5-min land surface temperature products of the V4 and V5 collections, respectively).

The aggregation procedure (from 30 to $960 \mathrm{~m}$ resolution) shows distorting of the areal extent and boundary of the impervious surface. Further research is suggested to use an impervious percentage map that is created using measured multispectral bands at lower resolution like MODIS $(250 \mathrm{~m})$ for further evaluation of temperature estimation residuals. In addition, LST products of the in 2016 launched Sentinel-3 sensor with corresponding VNIR data could be used and tested.

The improved DisTrad approach using temperature estimation residuals parameterized using an exponential relation with impervious percentage was found to be especially applicable at the kilometer resolution of the thermal band of MODIS, and it is expected to yield similar results with other low thermal resolution sensors, e.g., NOAA AVHRR. For other sensors with higher resolution thermal products, such as Landsat 5 TM, Landsat 7 ETM+ and ASTER08, the temperature estimation residuals parameterization is less suitable due to the fact the temperature estimation residuals at this resolution have a lower correlation with impervious percentage.

Six MODIS/Terra land surface temperature products were evaluated for thermal downscaling: 5-min, 1-Day and 8-Day products (respectively "MOD11_L2", "MOD11A1", and "MOD11A2"), collected with two different methods (V4 and V5) at $960 \mathrm{~m}$ resolution. Only the MODIS/Terra 5-min land surface temperature products (V4 and V5) "MOD11_L2" were downscaled and evaluated, using reference data consisting of a time-coincident land surface temperature product (derived by Essa et al. [26]) of a Landsat 7 ETM+ scene acquired on 24 May 2001. 
The downscaling of temporally averaged land surface temperature products of MODIS/Terra, such as 1-Day "MOD11A1" and 8-Day "MOD11A2", is not feasible using the DisTrad method. Although the impervious percentage does not show temporal variability on a time scale of one to eight days, a regression with land surface temperatures resulting from different meteorological conditions will not be representative. On the other hand, such a regression could be used in DisTrad to get an indication of patterns of land surface temperatures in the MODIS scene, rather than an accurate representation of subpixel temperatures. Relative temperature values may also be used to compare UHIs estimated for cities of different sizes under different climatic conditions and with multi-temporal studies of UHIs of a single city over four seasons using different satellite data.

The bias between the thermal sensors was high. It is possible that these different sources of data (Landsat and MODIS) can be used synergistically. Higher-resolution and less frequent thermal infrared observations from Landsat might be used to understand the spatial variation within coarser-resolution observations made by MODIS, which provide more frequent measurements [53]. The errors introduced, however, depend on meteorological conditions and the scale and magnitude of the surface contrast at the sub-pixel or sub-grid resolution [59]. Because of sensors thermal bias, their relative differences and not the absolute values may be useful to validate thermal downscaling of products, which are not time dependent like 1-Day and 8-Day of MODIS.

Due to the MODIS sensor quality assurance technicalities (e.g., algorithms and filters), MODIS land surface temperature V5 has a smaller range than V4. This may limit improving the relationship between impervious percentage and land surface temperature.

The relation between impervious percentage and MODIS land surface temperature products depend on the site, date, time and meteorological conditions. Hence, selection of uniform pixels of impervious percentage to improve the correlation with land surface temperature was not applicable. It is recommended to use the full range of impervious percentage and land surface temperature data. Moreover, selection of uniform pixels based on the coefficient of variance (CV) gave better results with images of high-resolution sensors, e.g., Landsat 7 ETM+ $(60 \mathrm{~m}$ resolution), while the selection procedure gave worse results when applied to low-resolution sensors, e.g., MODIS/Terra products (960 m resolution). Further studies should aim at developing better selection techniques for MODIS/Terra land surface temperature pixels to improve the correlation with impervious percentage.

The improved DisTrad downscaling algorithm does appear to have the potential to generate useful high spatial resolution land surface temperature information from MODIS thermal images. Further assessment of the improved DisTrad technique to downscale urban surface temperature in other urban areas with different climate and impervious percentage characteristics are important in order to obtain a higher degree of confidence in the estimations. Further studies on improving the temperature estimation residuals using other physical, statistical, and mathematical approaches are recommended.

Acknowledgments: MODIS images were obtained from the EOS Data Gateway at http:/ / redhook.gsfc.nasa.gov. This research was under the framework of a PhD study supported by an ERASMUS MUNDUS Scholarship programme based on the bilateral agreement between Al-AQSA University (Palestine) and the EU. The research presented in this paper is funded by the Belgian Science Policy Office in the frame of the STEREO II programme-project MAMUD (SR/00/105) (MAMUD, 2010). The first author acknowledges the Geospatial Data Center for Education Research and Development (GDC)/Al-Aqsa University for providing office space and infrastructure to achieve this article.

Author Contributions: Wiesam Essa and Boud Verbeiren conceived and designed the experiments; Wiesam Essa performed the experiments; Wiesam Essa analyzed the data; Wiesam Essa, Boud Verbeiren, Johannes van der Kwast, and Okke Batelaan wrote the paper.

Conflicts of Interest: The authors declare no conflict of interest.

\section{References}

1. Liu, Y.; Hiyama, T.; Yamaguchi, Y. Scaling of land surface temperature using satellite data: A case examination on ASTER and MODIS products over a heterogeneous terrain area. Remote Sens. Environ. 2006, 105, 115-128. [CrossRef] 
2. Stathopoulou, M.; Cartalis, C. Downscaling AVHRR land surface temperatures for improved surface urban heat island intensity estimation. Remote Sens. Environ. 2009, 113, 2592-2605. [CrossRef]

3. Xu, H.; Ding, F.; Wen, X. Urban Expansion and Heat Island Dynamics in the Quanzhou Region, China. IEEE J. Sel. Top. Appl. Earth Obs. Remote Sens. 2009, 2, 74-79. [CrossRef]

4. Mensink, C.; Lewyckyj, N.; Janssen, L. A new concept for air quality modeling in street canyons. Water Air Soil Pollut. Focus 2002, 2, 339-349. [CrossRef]

5. Lo, C.; Quattrochi, D.; Luvall, J. Application of high-resolution thermal infrared remote sensing and GIS to assess the urban heat island effect. Int. J. Remote Sens. 1997, 18, 287-304. [CrossRef]

6. Nichol, J. High-resolution surface temperature patterns related to urban morphology in a tropical city: A satellite-based study. J. Appl. Meteorol. 1996, 35, 135-146. [CrossRef]

7. Tucker, C.J.; D'Souza, G.; Belward, A.S.; Malingreau, J.-P. (Eds.) Advances in the Use of NOAA AVHRR Data for Land Applications; Springer: Dordrecht, The Netherlands, 1996.

8. Zhou, J.; Zhang, X.; Zhan, W.; Zhang, H. Land surface temperature retrieval from MODIS data by integrating regression models and the genetic algorithm in an arid region. Remote Sens. 2014, 6, 5344-5367. [CrossRef]

9. Sòria, G.; Sobrino, J.A. ENVISAT / AATSR derived land surface temperature over a heterogeneous region. Remote Sens. Environ. 2007, 111, 409-422. [CrossRef]

10. Coppo, P.; Smith, D.; Nieke, J. Sea and Land Surface Temperature Radiometer on Sentinel-3. In Optical Payloads for Space Missions; John Wiley \& Sons, Ltd.: Hoboken, NJ, USA, 2015; pp. 701-714.

11. Sobrino, J.A.; Jiménez-Muñoz, J.C.; Paolini, L. Land surface temperature retrieval from LANDSAT TM 5. Remote Sens. Environ. 2004, 90, 434-440. [CrossRef]

12. Tan, K.; Liao, Z.; Du, P.; Wu, L. Land surface temperature retrieval from Landsat 8 data and validation with geosensor network. Front. Earth Sci. 2016. [CrossRef]

13. Wang, K.; Liang, S. Evaluation of ASTER and MODIS land surface temperature and emissivity products using long-term surface longwave radiation observations at SURFRAD sites. Remote Sens. Environ. 2009, 113, 1556-1565. [CrossRef]

14. Rahman, M.T.; Aldosary, A.S.; Mortoja, M.G. Modeling future land cover changes and their effects on the land surface temperatures in the Saudi Arabian eastern coastal city of Dammam. Land 2017, 6, 36. [CrossRef]

15. Liu, H.; Weng, Q. An examination of the effect of landscape pattern, land surface temperature, and socioeconomic conditions on WNV dissemination in Chicago. Earth Environ Sci. Environ. Mon. Assess. 2009, 159, 143-161. [CrossRef] [PubMed]

16. Wan, Z.; Dozier, J. A generalized split-window algorithm for retrieving land-surface temperature from space. IEEE Trans. Geosci. Remote Sens. 1996, 34, 898-905.

17. Gillespie, A.; Rokugawa, S.; Matsunaga, T.; Cothern, J.; Hook, S.; Kahle, A. A temperature and emissivity separation algorithm for Advanced Spaceborne Thermal Emission and Reflection Radiometer (ASTER) images. IEEE Trans. Geosci. Remote Sens. 1998, 36, 1113-1126. [CrossRef]

18. Qin, Z.; Karnieli, A.; Berliner, P. A mono-algorithm for retrieving land surface temperature from Landsat TM data and its application to the Israel-Egypt border region. Int. J. Remote Sens. 2001, 22, 583-594. [CrossRef]

19. Pu, R.; Gong, P.; Michishita, R.; Sasagawa, T. Assessment of Multi-Resolution and Multi-Sensor Data for Urban Surface Temperature Retrieval. Remote Sens. Environ. 2006, 104, 211-225. [CrossRef]

20. Zhukov, B.; Oertel, D.; Lanzl, F.; Reinhackel, G. Unmixing-based multisensor multiresolution image fusion. IEEE Trans. Geosci. Remote Sens. 1999, 37, 1212-1226. [CrossRef]

21. Kustas, W.; Norman, J.; Anderson, M.; French, A. Estimating subpixel surface temperatures and energy fluxes from the vegetation index-Radiometric temperature relationship. Remote Sens. Environ. 2003, 85, 429-440. [CrossRef]

22. Agam, N.; Kustas, W.; Anderson, M.; Li, F.; Neale, C. A vegetation index based technique for spatial sharpening of thermal imagery. Remote Sens. Environ. 2007, 107, 545-558. [CrossRef]

23. Liu, D.; Pu, R. Downscaling thermal infrared radiance for subpixel land surface temperature retrieval. Sensors 2008, 8, 2695-2706. [CrossRef] [PubMed]

24. Dominguez, A.; Kleissl, J.; Luvall, J.; Rickman, R. High-resolution urban thermal sharpener (HUTS). Remote Sens. Environ. 2011, 115, 1772-1780. [CrossRef]

25. Voogt, J.A.; Oke, T.R. Thermal remote sensing of urban climates. Remote Sens. Environ. 2003, 86, 370-384. [CrossRef] 
26. Essa, W.; Verbeiren, B.; van der Kwast, J.; Batelaan, O. Evaluation of DisTrad Thermal Sharpening for Urban Areas. Int. J. Appl. Earth Obs. Geoinf. 2012, 19, 163-172. [CrossRef]

27. Zhang, X.; Zhong, T.; Wang, K.; Cheng, Z. Scaling of impervious surface area and vegetation as indicators to urban land surface temperature using satellite data. Int. J. Remote Sens. 2009, 30, 841-859. [CrossRef]

28. Liu, P.; Du, P.; Wen, C.; Xia, J. Evaluation of urban heat environment using multi-algorithm and multi-scale images. In Proceedings of the Joint Urban Remote Sensing Event, Shanghai, China, 20-22 May 2009.

29. Essa, W.; Verbeiren, B.; van der Kwast, J.; Batelaan, O. Downscaling of thermal images over urban areas using the land surface temperature-Impervious percentage relationship. Int. J. Appl. Earth Obs. Geoinf. 2013, 23, 95-108. [CrossRef]

30. Van de Voorde, T.; Jacquet, W.; Canters, F. Mapping form and function in urban areas: An approach based on urban metrics and continuous impervious surface data. Landsc. Urban Plan. 2011, 102, 143-155. [CrossRef]

31. Eswar, R.; Sekhar, M.; Bhattacharya, B.K. Disaggregation of LST over India: Comparative analysis of different vegetation indices. Int. J. Remote Sens. 2016, 37, 1035-1054. [CrossRef]

32. Gao, L.; Zhan, W.; Huang, F.; Zhu, X.; Zhou, J.; Quan, J.; Du, P.; Li, M. Disaggregation of remotely sensed land surface temperature: A simple yet flexible index (SIFI) to assess method performances. Remote Sens. Environ. 2017, 200, 206-219. [CrossRef]

33. Mukherjee, S. Multi-Resolution Technique for Disaggregation of Thermal Image Using Vegetation Index. Master's Thesis, ITC International Institute for Geo-Information Science and Earth Observation of the University of Twente, Twente, The Netherlands, 2008.

34. Agam, N.; Kustas, W.; Anderson, M.; Li, F.; Colaizzi, P. Utility of thermal sharpening over Texas high plains irrigated agricultural fields. J. Geophys. Res. 2007, 112, 19110-19120. [CrossRef]

35. Gao, F.; Kustas, W.; Anderson, M. A data mining approach for sharpening thermal satellite imagery over land. Remote Sens. 2012, 4, 3287-3319. [CrossRef]

36. Bisquert, M.; Sánchez, J.M.; Caselles, V. Evaluation of Disaggregation Methods for Downscaling MODIS Land Surface Temperature to Landsat Spatial Resolution in Barrax Test. IEEE J. Sel. Top. Appl. Earth Obs. Remote Sens. 2016, 9. [CrossRef]

37. Bechtel, B.; Zakšek, K.; Hoshyaripour, G. Downscaling land surface temperature in an urban area: A case study for Hamburg, Germany. Remote Sens. 2012, 4, 3184-3200. [CrossRef]

38. Merlin, O.; Duchemin, O.; Hagolle, O.; Jacob, F.; Coudert, B.; Chehbouni, G.; Dedieu, G.; Garatuza, J.; Kerr, Y. Disaggregation of MODIS surface temperature over an agricultural area using a time series of Formosat-2 images. Remote Sens. Environ. 2010, 114, 2500-2512. [CrossRef]

39. Anderson, M.C.; Norman, J.M.; Mecikalski, J.R.; Torn, R.D.; Kustas, W.P.; Basara, J.B. A multiscale remote sensing model for disaggregating regional fluxes to micrometeorological scales. J. Hydrometeorol. 2004, 5, 343-363. [CrossRef]

40. Bindhu, V.M.; Narasimhan, B.; Sudheer, K.P. Development and Verification of a Non-Linear Disaggregation Method (Nl-Distrad) to Downscale MODIS Land Surface Temperature to the Spatial Scale of Landsat Thermal Data to Estimate Evapotranspiration. Remote Sens. Environ. 2013, 135, 118-129. [CrossRef]

41. Van de Voorde, T.; van der Kwast, J.; Uljee, I.; Engelen, G.; Canters, F. Improving the calibration of the MOLAND urban growth model with land-use information derived from a time-series of medium resolution remote sensing data. In Proceedings of the International Conference on Computational Science and Its Applications, Fukuoka, Japan, 23-26 March 2010; Taniar, D., Gervasi, O., Murgante, B., Pardede, E., Apduhan, B.O., Eds.; Springer: Berlin, Germany, 2010; pp. 89-104.

42. Wan, Z. Collection-5 MODIS Land Surface Temperature Products Users' Guide; University of California: Santa Barbara, CA, USA, 2007.

43. Inamdar, A.K.; French, A. Disaggregation of GOES land surface temperatures using surface emissivity. Geophys. Res. Lett. 2009, 36. [CrossRef]

44. Ma, Y.; Kuang, Y.; Huang, N. Coupling urbanization analyses for studying urban thermal environment and its interplay with biophysical parameters based on TM/ETM+ imagery. Int. J. Appl. Earth Obs. Geoinf. 2010, 12, 110-118. [CrossRef]

45. Wu, H.; Li, Z. Scale Issues in Remote Sensing: A Review on Analysis, Processing and Modeling. Sensors 2009, 9, 1768-1793. [CrossRef] [PubMed]

46. Lam, N.; Quattrochi, D. On the issues of scale, resolution, and fractal analysis in the mapping sciences. Prof. Geogr. 1992, 44, 88-98. [CrossRef] 
47. Bian, L. Multiscale Nature of Spatial Data in Scaling up Environmental Models. In Scale in Remote Sensing and GIS; Quattrochi, D.A., Goodchild, M.F., Eds.; Lewis Publishers: Boca Raton, FL, USA, 2002; pp. $13-26$.

48. Cao, C.Y.; Lam, N. Understanding the scale and resolution effects in remote sensing and GIS. In Scale in Remote Sensing and GIS; Quattrochi, D.A., Goodchild, M.F., Eds.; Lewis Publishers: Boca Raton, FL, USA, 1997; pp. 57-72.

49. Bierkens, M.; Finke, P.; De Willigen, P. Upscaling and Downscaling Methods for Environmental Research; Kluwer Academic Publishers: Dordrecht, The Netherlands, 2000.

50. Bauer, M.E.; Doyle, J.K.; Heinert, N.J. Impervious surface mapping using satellite remote sensing. In Proceedings of the IEEE International Geoscience and Remote Sensing Symposium, Toronto, ON, Canada, 24-28 June 2002; pp. 2334-2336.

51. Norman, J.M.; Becker, F. Terminology in thermal infrared remote sensing of natural surfaces. Agric. For. Meteorol. 1995, 77, 153-166. [CrossRef]

52. Norman, J.M.; Divakarla, M.; Goel, N.S. Algorithms for exacting information from remote Thermal-IR observations of the Earth's surface. Remote Sens. Environ. 1995, 51, 157-168. [CrossRef]

53. Rubio, E.; Caselles, V.; Badenas, C. Emissivity measurements of several soils and vegetation types in the 8-14 $\mu \mathrm{m}$ wave band: Analysis of two field methods. Remote Sens. Environ. 1997, 59, 490-521. [CrossRef]

54. Van der Kwast, J. Quantification of Top Soil Moisture Patterns: Evaluation of Field Methods, Process-Based Modelling, Remote Sensing and an Integrated Approach. Ph.D. Thesis, Utrecht University, Utrecht, The Netherlands, 2009.

55. Li, F.; Jackson, T.; Kustas, W.; Schmugge, T.; French, A.; Cosh, M.; Bindlish, R. Deriving land surface temperature from Landsat 5 and 7 during SMEX02/SMACEX. Remote Sens. Environ. 2004, 92, 521-534. [CrossRef]

56. Guo, L.J.; Moore, J.M. Pixel block intensity modulation: Adding spatial detail to TM band 6 thermal imagery. Int. J. Remote Sens. 1998, 19, 2477-2491. [CrossRef]

57. Van de Voorde, T.; Demarchi, L.; Canters, F. Multi-temporal spectral unmixing to characterize urban change in the Greater Dublin area. In Proceedings of the Remote Sensing for a Changing Europe, Istanbul, Turkey, 2-7 June 2008; IOS Press: Amsterdam, The Netherlands, 2008; pp. 276-283.

58. Ye, Z.; Gong, H.; Zhao, W. Sub-pixel urban area thermal pattern analysis using ASTER and SPOT-5. In Proceedings of the Joint Urban Remote Sensing Event, Shanghai, China, 20-22 May 2009.

59. Kustas, W.; Norman, J.M. Evaluating the effects of subpixel heterogeneity on pixel average fluxes. Remote Sens. Environ. 2000, 74, 327-342. [CrossRef] 